\title{
Validation of geolocation estimates based on light level and sea surface temperature from electronic tags
}

\author{
Steven L. H. Teo, Andre Boustany, Susanna Blackwell, Andreas Walli, \\ Kevin C. Weng, Barbara A. Block*
}

Tuna Research and Conservation Center, Stanford University, Hopkins Marine Station, 120 Oceanview Boulevard, Pacific Grove, California 93950, USA

\begin{abstract}
Electronic tags have enhanced our understanding of the movements and behavior of pelagic animals by providing position information from the Argos system satellites or by geolocation estimates using light levels and/or sea surface temperatures (SSTs). The ability to geolocate animals that remain submerged is of great value to fisheries management, but the accuracy of these geolocation estimates has to be validated on free-swimming animals. In this paper, we report double-tagging experiments on free-swimming salmon sharks Lamna ditropis and blue sharks Prionace glauca, tagged with satellite telemetry and pop-up satellite tags, which provide a direct comparison between Argos positions and geolocation estimates derived from light levels and SSTs. In addition, the Argosbased pop-up satellite tag endpoints and GPS-based recapture locations of Atlantic bluefin tunas Thunnus thynnus were compared with the last geolocation estimates from pop-up satellite and archival tags. In the double-tagging experiments, the root mean square errors of the light level longitude estimates were 0.89 and $0.55^{\circ}$; while for SST latitude estimates, the root mean square errors were 1.47 and $1.16^{\circ}$ for salmon sharks and blue sharks respectively. Geolocation estimates of Atlantic bluefin tuna, using archival data from surgically implanted archival tags or recovered pop-up satellite tags, had root mean square errors of 0.78 and $0.90^{\circ}$ for light level longitude and SST latitude estimates, respectively. Using data transmitted by pop-up satellite tags deployed on Atlantic bluefin tunas, the light level longitude and SST latitude estimates had root mean square errors of 1.30 and $1.89^{\circ}$, respectively. In addition, a series of computer simulations were performed to examine which variables were most likely to influence the accuracy of SST latitude estimates. The simulations indicated that the difference between the SST measured by the electronic tag and the remotely sensed SST at a given location was the predominant influence on the accuracy of SST latitude estimates. These results demonstrate that tag-measured SSTs can be used in conjunction with light level data to significantly improve the geolocation estimates from electronic tags.
\end{abstract}

KEY WORDS: Lamna ditropis · Prionace glauca $\cdot$ Thunnus thynnus $\cdot$ Geolocation accuracy $\cdot$ Pop-up satellite tag $\cdot$ Archival tag

Resale or republication not permitted without written consent of the publisher

\section{INTRODUCTION}

Determining the detailed movements and habitat use patterns of highly migratory pelagic animals in the open ocean is critical for understanding their ecology (Block et al. 2001, 2002, Polovina et al. 2001). One of the most effective ways to gain insight into the biology of highly migratory pelagic species is to merge movement and behavioral data acquired by electronic tags with in situ and remotely sensed oceanographic information. However, accurate knowledge of the animal's location is required to integrate this information.

Satellite telemetry has been successfully used to track pelagic air-breathing animals (McConnell et al. 1999, Mate et al. 2000, Nichols et al. 2000, Polovina et al. 2000, Costa et al. 2001), or animals that spend a large amount of time on the surface, such as sharks (Priede 1984, Eckert \& Stewart 2001, Eckert et al. 
2002). Satellite telemetry tags provide accurate locations by using the Argos system or the Global Positioning System (GPS). The Argos system uses the Doppler shift of radio transmissions from the tags to estimate location and can provide highly accurate locations (Taillade 1992). More recently, GPS tags have been used in several studies to track marine mammals and albatrosses, but relatively few locations were obtained for the marine mammals (Sisak 1998, Jay \& Garner 2002, Weimerskirch et al. 2002). However, satellite telemetry tags have rarely been used on fishes that remain constantly submerged because radio signals do not transmit through water. Studies have focused on using surgically implanted archival tags or externally placed pop-up satellite tags. These types of electronic tags have allowed researchers to directly examine the short- and long-term movement patterns and behavior of numerous fish species, including tunas (Block et al. 1998a, 2001, Gunn \& Block 2001, Kitagawa et al. 2001, Marcinek et al. 2001, Schaefer \& Fuller 2002, Musyl et al. 2003), billfishes (Graves et al. 2002, Gunn et al. 2003, Kerstetter et al. 2003, Takahashi et al. 2003), sharks (West \& Stevens 2001, Boustany et al. 2002, Weng \& Block 2004), eels (Jellyman \& Tsukamoto 2002), molas (Seitz et al. 2002) and flatfishes (Metcalfe \& Arnold 1997, Hunter et al. 2003).

Implantable archival and pop-up satellite tags are now routinely used to estimate the location of fishes using light level data collected from an external light sensor on the tags. The light level data are processed onboard or post-processed after the data is downloaded, to estimate day length and the time of local noon or midnight. Latitude is then estimated from day length while longitude is estimated from the time of local noon or midnight (Wilson et al. 1992, Hill 1994, Hill \& Braun 2001, Ekstrom 2004). The accuracy of the geolocation estimates influences the optimal spatial scale on which to assess the relationship between the tagged animals and physical oceanographic conditions (Bradshaw et al. 2002). Therefore, improving these geolocation estimates and determining their error distributions are important priorities in the field of electronic tagging (Gunn \& Block 2001).

Previous studies have assessed the accuracy of light level geolocation estimates and shown that light level longitude estimates are more accurate and robust than light level latitude estimates (Gunn et al. 1994, Welch \& Eveson 1999, 2001, Musyl et al. 2001). However, these studies were based on electronic tags that were attached to fixed buoys, moving ships or tunas in shallow $(<20 \mathrm{~m})$ cages. These error estimates are therefore likely to be underestimates for tags attached to free-swimming animals (Gunn \& Block 2001). These previous studies did not account for diving activity, which degrades the accuracy of a light level geolocation estimate, especially latitude. In addition, these error estimates did not include latitude estimates around the equinoxes. All latitudes have similar day lengths during these periods, making it very difficult to estimate latitudes from day length. This would have biased the error estimates towards smaller values. Therefore, it is important to assess the accuracy of the geolocation estimates on free-swimming animals in the wild under all conditions.

Due to the challenges of estimating latitudes from light level data, several studies have used sea surface temperatures (SSTs) in conjunction with light levels to improve latitude estimates (Delong et al. 1992, Block et al. 2001, Inagake et al. 2001, Beck et al. 2002, Kitagawa et al. 2002, Sims et al. 2003). The concept of using SST to estimate latitude was suggested by Smith \& Goodman (1986). The authors concluded, 'the archival tag appears to offer considerable potential for determining historical fish position, inferring longitude from time of sunrise and sunset, and inferring latitude from temperature at depth (temperature at or near zero depth is the SST) relative to a reference field'. In the open ocean, there is a SST gradient along a longitudinal meridian, with SSTs generally becoming cooler towards the poles. The SSTs recorded by the electronic tag can be matched with a reference, remotely sensed SST grid, along the longitude estimated from light levels for that day. If the hemisphere in which the animal is located is known, the latitude at which the SSTs measured by the tag best match the remotely sensed SSTs should closely approximate the actual latitude for the day. However, there have not been adequate assessments of the accuracy of SST latitude estimates and the sources of errors associated with them.

The objectives of this study were to describe an SST latitude estimation algorithm and assess the accuracy of the geolocation estimates on 3 species of large pelagic fishes, rather than fixed buoys. The use of freeswimming fishes released into the open ocean provided a test of whether such algorithms would perform well when vertical movements were not limited. Since location estimates from the Argos satellite system are highly accurate, they were compared with light level and SST geolocation estimates using salmon sharks Lamna ditropis and blue sharks Prionace glauca that were simultaneously carrying both satellite telemetry tags and pop-up satellite tags (Block et al. 2002, Phillips et al. 2004). In addition, the Argos or GPSbased endpoint locations of Atlantic bluefin tunas Thunnus thynnus, which were tagged with pop-up satellite or implantable archival tags, were compared with the last on-fish geolocation estimates using light levels and SSTs (Schaefer \& Fuller 2002). Finally, a series of computer simulations were used to examine the factors affecting the accuracy of the SST latitude estimates. 


\section{MATERIALS AND METHODS}

The salmon sharks and blue sharks were doubletagged with a SPOT 2.0 satellite telemetry tag (Wildlife Computers, Hardware Version 2.0) and a PAT 2.0 popup satellite tag (Wildlife Computers, Hardware Version 2.0, Software Version 2.08.0008). The Atlantic bluefin tunas were tagged with either a PAT 2.0 tag or an implantable archival tag. The archival tags used in this study were the LTD 2310 archival tag (Lotek Wireless), the NMT v1.1 archival tag (Northwest Marine Technology and Lotek Wireless) and the Mk7 archival tag (Wildlife Computers).

SPOT 2.0 tags. The SPOT 2.0 tags are satellite telemetry tags that provided location estimates from the Argos satellite system. The tags transmitted data to the Argos system when the sharks were on the ocean surface and the conductivity sensor on the tag was exposed to air. The Argos satellite system uses the Doppler shift of the tag's radio transmissions to estimate the longitude and latitude of the tag (Taillade 1992). A quality index is assigned to each Argos location (termed the location class or LC) and error estimates for locations designated LC 1, 2 or 3 are provided by Argos. Argos states that the standard deviation of the location errors is $150 \mathrm{~m}$ for LC 3, $350 \mathrm{~m}$ for LC 2, and $1000 \mathrm{~m}$ for LC 1 (Taillade 1992). However, the precision of these locations may be better than stated by Argos (Vincent et al. 2002). The daily mean longitudes and latitudes from these tags were calculated from locations with $\mathrm{LC} \geq 1$. The errors of Argos locations were probably 2 orders of magnitude smaller than the likely errors associated with light level and SST geolocation. Therefore, our assumption that the location estimates from Argos with LC $\geq 1$ represents the actual location of an animal is reasonable.

PAT 2.0 tags. The pop-up satellite tags used in this study recorded ambient temperature, pressure and light level data every $60 \mathrm{~s}$. On a preprogramed date, the PAT 2.0 tag detached from the animal, surfaced, and transmitted a summary of the sampled data to the Argos system over 6 to $12 \mathrm{~d}$. The Argos system calculated the pop-up endpoint location of the tag using the
Doppler shift of the radio transmissions. The pop-up endpoint location was based on the first Argos location, with $\mathrm{LC} \geq 1$. The tags automatically selected and transmitted portions of the light level data that were representative of sunrise and sunset. We used 12 evenly distributed points to reconstruct each sunrise or sunset. A proprietary software package from the tag manufacturer (PatDecoder 7.08.0005, Wildlife Computers) was used to correct for light attenuation and to estimate longitudes and latitudes from the transmitted light level data. The longitude was estimated by calculating the time difference between local midday or midnight, and midday or midnight along the Greenwich meridian, and using the time difference in standard astronomical algorithms (see Delong et al. 1992, Wilson et al. 1992, Hill 1994, Ekstrom 2004 for detailed descriptions of the algorithms). All light level data were visually inspected and grossly incorrect light curves were not used for subsequent analysis. If a PAT 2.0 tag was recovered, the full archival data set consisting of ambient temperature, pressure and light level data every 2 min was retrieved.

Archival tags. The LTD 2310, NMT v1.1 and Mk7 archival tags were programed to archive the light level, pressure, body and ambient temperatures, every $120 \mathrm{~s}$ (LTD 2310 and Mk7) or $128 \mathrm{~s}$ (NMT v1.1). In addition, the LTD 2310 also recorded pressure and light level every $60 \mathrm{~s}$ that were used to estimate light level geolocations. The LTD 2310 and NMT v1.1 tags had onboard software that processed the light level and pressure data, corrected for light attenuation, and logged the estimated longitude and latitude into the 'day log'. The light level data from the Mk7 archival tag were post-processed using a proprietary software package from the tag manufacturer to correct for light attenuation and to estimate the light level longitudes and latitudes (Geocontrol v2.01, Wildlife Computers). Similar to the PAT 2.0 tags, all light level data from the Mk7 tags were visually inspected and grossly incorrect light level data were not used for subsequent analysis. If a PAT 2.0 tag was recovered and provided the full archival data set, the light level data were processed in the same way as for the Mk7 archival tags (Table 1).

Table 1. Lamna ditropis, Prionace glauca and Thunnus thynnus. Summary of tag deployments and track durations (mean \pm SD) for salmon sharks, blue sharks and Atlantic bluefin tunas. n: number of individuals. No. of validations: total number of geolocation estimates used to assess accuracy of geolocation estimates. Lengths of salmon sharks and Atlantic bluefin tunas are curved fork lengths; lengths of blue sharks are total lengths; both are means $\pm \mathrm{SD}$

\begin{tabular}{|lrccll|}
\hline Species & $\mathrm{n}$ & $\begin{array}{c}\text { Length at } \\
\text { tagging }(\mathrm{cm})\end{array}$ & $\begin{array}{c}\text { Duration } \\
(\mathrm{d})\end{array}$ & Type of tag & $\begin{array}{c}\text { No. of } \\
\text { validations }\end{array}$ \\
\hline Salmon shark & 2 & $202 \pm 8$ & $123 \pm 0$ & SPOT 2.0 satellite telemetry tag and PAT 2.0 pop-up satellite tag & 92 \\
Blue shark & 4 & $217 \pm 12$ & $66 \pm 38$ & SPOT 2.0 satellite telemetry tag and PAT 2.0 pop-up satellite tag & 46 \\
Atlantic bluefin tuna & 49 & $208 \pm 18$ & $117 \pm 48$ & PAT 2.0 pop-up satellite tag with transmitted data & 49 \\
Atlantic bluefin tuna & 8 & $212 \pm 10$ & $173 \pm 41$ & Recovered PAT 2.0 pop-up satellite tag with archival data & 8 \\
Atlantic bluefin tuna & 3 & $211 \pm 20$ & $369 \pm 230$ & LTD2310, NMT v1.1 and Mk 7 implantable archival tags & 3 \\
\hline
\end{tabular}


The recapture positions of the archival tags and the recaptured pop-up satellite tags were recorded by their respective fishers, using GPS.

Shark double-tagging experiments. Double-tagging experiments with satellite telemetry tags and pop-up satellite tags were conducted on 2 salmon sharks and 4 blue sharks (Table 1). The salmon sharks were caught by handline in Prince William Sound, Alaska, from the RV 'Montague' on 14 July 2002. The blue sharks were caught by pelagic longline deployed in the southern California Bight from the RV 'David Starr Jordan' from 24 June 2002 to 5 July 2002. Both species were brought aboard the vessel on a stretcher, and a SPOT 2.0 tag was attached to the dorsal fin using 3 stainless steel bolts $(4 \mathrm{~mm} \varnothing)$ that were sterilized with Betadine solution (Purdue Pharma). At the same time, a PAT 2.0 tag was attached to the base of the dorsal fin using a titanium dart and monofilament leader (Block et al. 1998a). A loop was fastened around the ground ring to hold the tag close to the shark. All the animals were released back into the ocean in a healthy condition; three of the SPOT 2.0 tags put on the salmon sharks were still transmitting accurate locations $(\mathrm{LC} \geq 1) 19$ mo after deployment. The satellite telemetry tags from the double-tagged sharks provided $0.7 \pm 1.3$ accurate locations per day (mean $\pm \mathrm{SD}$ ). Of the 6 pop-up satellite tags, 5 remained on the salmon sharks and blue sharks until the programed pop-up date (2 to 4 mo durations). For one of the blue sharks, the pop-up satellite tag prematurely released 2 mo after deployment. This tag was floating on the surface for $4 \mathrm{~d}$ before it began transmitting. Only data from the period when the popup satellite tag was still attached to the shark were used for this study.

The light level data from all PAT 2.0 tags were used to estimate longitude and latitude. Outliers were removed from the longitude estimates using a modified version of the iterative forward/backward averaging filter (McConnell et al. 1992). The daily rate of change in longitude allowed by the filter was set at $2^{\circ}$. This only removed longitude estimates that were biologically unrealistic, since the mean rate of change in longitude measured by the SPOT 2.0 tags for salmon sharks and blue sharks were $0.21 \pm 0.22^{\circ} \mathrm{d}^{-1}$ (mean \pm $\mathrm{SD})$ and $0.23 \pm 0.26^{\circ} \mathrm{d}^{-1}$ respectively. To determine its effect, we also estimated the errors of the unfiltered longitude estimates.

The light level longitude estimates and the SST data from the depth-temperature profiles of the PAT 2.0 tags were used to estimate the latitudes. For this study, the geolocation estimates for the salmon sharks were calculated after the sharks had left Prince William Sound and entered the Gulf of Alaska. For the blue sharks in the eastern Pacific, geolocation estimates were made for all the days that valid light and SST data were received. If more than one longitude estimate was available for a $24 \mathrm{~h}$ period, we used the longitude estimate that minimized the distance traveled between adjacent points. The SST data extraction process and the latitude estimation algorithm are described below. The errors in the light level and SST geolocation estimates were calculated by the differences between the geolocation estimates and the mean of the SPOT 2.0 locations ( $\mathrm{LC} \geq 1$ ) from the corresponding day (Table 1).

Atlantic bluefin tuna experiments. The geolocation estimates from 60 Atlantic bluefin tunas, which were tagged with PAT 2.0 pop-up satellite tags or implantable archival tags, were compared with Argosbased pop-up satellite tag endpoint positions or GPS-based recapture locations (Table 1). These fish were part of large-scale tagging experiments, and the experimental procedures have been described previously (Block et al. 1998a,b, 2001). The bluefin tunas were caught by rod and reel, and brought aboard the vessel. The bluefin tunas were then tagged with a pop-up satellite tag or an implantable archival tag. The PAT 2.0 tags were attached to the base of their second dorsal fins with a titanium dart and monofilament leader $(\mathrm{n}=57$, Table 1$)$. The NMT v1.1 ( $\mathrm{n}=1)$, LTD $2310(\mathrm{n}=1)$, and $\operatorname{Mk} 7(\mathrm{n}=1)$ archival tags were surgically implanted into the peritoneal cavity of the bluefin tunas (Table 1). All tunas were released back into the ocean in a healthy condition.

The pop-up satellite tag endpoint locations or recapture positions of the Atlantic bluefin tunas were compared with the final geolocation estimates using light level and SST, prior to pop-up or recapture (Table 1). For this analysis, we only used data sets from tags that generated light level and SST geolocation estimates within $5 \mathrm{~d}$ of pop-up or recapture and were on the fish for more than $30 \mathrm{~d}$. In addition, the pressure data from the tags were inspected to ensure that only on-fish data were used for further analysis (i.e. no drifter data). The light level data were then used to estimate longitude and latitude. Outliers were removed from the longitude estimates using a modified version of the iterative forward/backward averaging filter (McConnell et al. 1992). The daily rate of change in longitude allowed by the filter was $2^{\circ}$, which only removed longitude estimates that were biologically unrealistic (Boustany et al. 2001). To determine its effect, we also estimated the errors of the unfiltered longitude estimates. The light level longitude estimates and the SST data collected by the tags were then used to estimate the latitudes, as described below.

Extracting SSTs from electronic tags. The SST distributions used for the latitude estimations were obtained from each tag, based on the tag's model, ther- 
mistor properties and onboard software. The full archival records were obtained from the LTD 2310, Mk7 and the recovered PAT 2.0 tags from Atlantic bluefin tunas. For all these tags, the ambient water temperatures recorded within $1 \mathrm{~m}$ of the surface were considered SSTs. The entire range of SSTs recorded by these tags was extracted and the proportion of time spent at each SST for each day was calculated. The pressure sensors on 2 of the archival and pop-up satellite tags drifted, with the largest drift being $8 \mathrm{~m}$ over 1.5 yr. We compensated for this drift prior to extracting the SSTs. The Atlantic bluefin tunas were assumed to have reached the surface at least once a day and a third-order polynomial was fitted to the minimum depth of each day of the track. The polynomial was then used to correct the pressure data of the tag by subtracting the polynomial from the raw pressure data. In order to improve the accuracy of the SSTs, it is important to correct for the thermal inertia of the electronic tags (Daunt et al. 2003). In laboratory experiments, we discerned that the ambient temperature sensors of the PAT 2.0 and LTD 2310 tags have time constants of $93 \pm 4.0$ and $2.4 \pm 0.2$ s respectively (mean $\pm \mathrm{SD}, \mathrm{n}=5$, time taken to record a $63 \%$ change in temperature for a step change from 25 to $10^{\circ} \mathrm{C}$ ). The ambient temperature sensors of the Mk7 and NMT v1.1 tags have manufacturer-specified time constants of 6 and $<3.0$ s respectively (R. Hill, Wildlife Computers; P. Ekstrom, Northwest Marine Technology). The thermal inertia of these tags was compensated by excluding the SST data during the time required for the sensor to equilibrate with the ambient surface temperature.

The recovered NMT v1.1 archival tag was programed to store data in 2 formats: (1) a 'day log' of daily summaries that included an estimated light level longitude and latitude, and a single SST; (2) approximately 2 mo of raw data (light level, depth, body and ambient temperature every $128 \mathrm{~s}$ ). For the first 2 mo, the SST distributions were extracted from the timeseries data, as described above for the other archival tags. For the remainder of the record, both longitude estimates and SSTs were obtained from the day log. Therefore, only $1 \mathrm{SST}$ was recorded per day after the first 2 mo. During the $24 \mathrm{~h}$ period starting from local midnight, the value for the SST was overwritten whenever the tag recorded an ambient water temperature at $0 \mathrm{~m}$. This SST reported by the tag in the day log is therefore the last ambient water temperature at $0 \mathrm{~m}$ during the $24 \mathrm{~h}$ period (P. Ekstrom pers. comm., Northwest Marine Technology). If the tag did not sample an ambient water temperature at $0 \mathrm{~m}$, the SST would then be extrapolated from 2 temperatures recorded during the day that were shallower than $20 \mathrm{~m}$ and more than $10 \mathrm{~m}$ apart. If this was also not possible, no SST was recorded for the day.
To extract SSTs from the PAT 2.0 tags that were not recovered, we used the PAT depth-temperature (PDT) profile function. During each time interval, the PDT function recorded the minimum and maximum temperatures experienced at the shallowest and deepest depths attained by the tagged fish, and at 6 additional depths between those points. The minimum and maximum temperatures at $0 \mathrm{~m}$ were considered SSTs and used to estimate latitude. In addition, the SST latitude algorithm required as an input the proportion of time spent at each SST. However, the PAT 2.0 tags used in this study did not transmit the proportion of time spent at each SST. It was therefore assumed that proportions were equal for all the SSTs transmitted by the tag. For example, if the pop-up satellite tag transmitted 2 SSTs on a given day, it was assumed that the fish had spent $50 \%$ of its surface time at each SST.

SST latitude estimation. The latitudes were estimated from the light level longitudes and the SST data. For a given day, the SST data recorded by the electronic tags were matched with a reference SST grid along the light level longitude estimate for the same day. The reference SST grids used in this study were primarily equal angle, global $8 \mathrm{~d}$ mean nighttime SST grids from the moderate resolution imaging spectroradiometer (MODIS) that had been validated (ftp://podaac.jpl.nasa.gov, thermal IR SST, $4 \mathrm{~km}$ and $0.1^{\circ} \mathrm{C}$ resolution, Wan et al. 2002). When MODIS data were unavailable, equal angle, global $8 \mathrm{~d}$ mean nighttime SST grids from the advanced very high-resolution radiometer (AVHRR) were used instead (ftp://podaac. jpl.nasa.gov, Pathfinder algorithm, $9 \mathrm{~km}$ and $0.15^{\circ} \mathrm{C}$ resolution, Kearns et al. 2000). Nighttime SST grids were used because solar heating in low wind conditions $\left(<6 \mathrm{~m} \mathrm{~s}^{-1}\right)$ can warm the skin of the sea surface (Donlon et al. 1999). This warming could increase the difference between the sea surface skin temperature estimated by satellites and the bulk sea surface temperature measured by the tag. Some of the Argos SPOT 2.0 locations from the salmon sharks $(2 \%)$ and blue sharks (13\%) had very high (>80\%) cloud cover within $100 \mathrm{~km}$. These high cloud locations were not used for further analysis. The endpoints of all the Atlantic bluefin tunas had cloud covers less than $80 \%$. Sea surface temperature cannot be used to differentiate between locations in the northern and southern hemispheres because of similar SST gradients. The hemispheric latitudinal limits were set from 0 to $70^{\circ} \mathrm{N}$ to restrict the SST matching process to the Northern hemisphere.

We restricted the SST matching process to the area that the fish could have realistically moved, based on acoustic tracking studies that provided information on daily speeds (Carey \& Scharold 1990, Boustany et al. 2001). This reduced computational time and the best- 
matching latitude within the local region was found rather than the best global match. We set a $1^{\circ}$ constraint on the daily latitudinal change of the animal. The algorithm searched an area $1^{\circ} \mathrm{N}$ to $1^{\circ} \mathrm{S}$ of the previous day's latitude estimate. To test the effect of this constraint, the latitude estimates were subsequently repeated with no constraint. This constraint was conservative since the mean daily latitudinal changes measured by the SPOT 2.0 tags for salmon sharks and blue sharks were $0.26 \pm 0.19$ and $0.19 \pm 0.25^{\circ} \mathrm{d}^{-1}$ (mean $\pm \mathrm{SD})$ respectively. If the period between latitude estimates was so long that the latitudinal limits exceeded the hemispheric latitudinal limits, the hemispheric latitudinal limits were used instead $\left(0\right.$ to $\left.70^{\circ} \mathrm{N}\right)$.

Once the latitude limits had been established, latitude estimation proceeded in a series of progressive steps. To begin, the pixel in the remotely sensed SST grid that intersects the light level longitude estimate and the northern latitudinal limit was identified. A search area was then established around the specified pixel. To determine the effect of search area size, 3 search area sizes were used $(50 \times 50 \mathrm{~km}, 100 \times 100 \mathrm{~km}$, and $200 \times 200 \mathrm{~km}$ ). The SSTs within this search area were compared to the SSTs measured by the tag to determine how well they matched. After this, the algorithm moved to the next pixel south of the original pixel and the process was repeated until the southern latitudinal limit was reached. For this algorithm, an individual in the open ocean was assumed to be moving within an area rather than being in a fixed location over a $24 \mathrm{~h}$ period. If the tagged fish occasionally surfaced, it would have sampled the ocean surface at multiple locations over the course of a day and recorded the SST distribution of the area in which it was moving. Therefore, the search area where the remotely sensed SSTs best matched the SSTs measured by the tag could be considered the area in which the fish was located. The center of the best-matching search area was considered the mean location of the fish for that given day. We used 3 indices in turn to match the SSTs.

The first index, $\sum_{i} p_{i}$ is the weighted sum of the number of matching SSTs, where $p_{i}$ is the proportion of the time the fish spent at the ith matching SST $\left( \pm 0.05^{\circ} \mathrm{C}\right)$ within the search area for the day. The search area with the highest score was considered the area where the fish was located. If the fish randomly sampled the ocean surface, the SSTs in which the animal spent most of its time were likely to be either the most common within the search area or to be located close to the mean position of the fish for that day. By weighting the number of matching SSTs with the proportion of time the fish spent at those temperatures, the algorithm increased the importance of the SSTs that were more common in the area or were located closer to the mean position of the fish. In addition, the heav- ier weighting of the more common SSTs reduced the chance that erroneous SSTs affected the latitude estimate. If more than one search area had the same score for the first index, the matching process was continued by calculating the second index scores for the tied search areas.

The second index, $\sum_{i} p_{i} N_{i}$, is the weighted sum of the number of matching pixels within the search area, where $p_{i}$ is the same as the first index and $N_{i}$ is the number of pixels within the search area with the ith matching SST $\left( \pm 0.05^{\circ} \mathrm{C}\right)$. The search area with the highest score was considered the area where the fish was located. This index was used because a search area with more pixels of matching SSTs would have a higher probability of a fish experiencing those SSTs. This second index was only used to break the ties of the first index because it would otherwise be biased towards search areas with only 1 or 2 matching temperatures but with large numbers of matching pixels. However, search areas with the same first index score would tend to have the same number of matching temperatures. If more than 1 search area had the same score for the second index, the matching process was continued by calculating the third index scores for the remaining tied search areas.

The third index, $\sum_{t}\left[p_{t}-E\left(p_{t}\right)\right]^{2}$, was the sum-ofsquares of the differences between the proportion of SSTs measured by the tag, $p_{t}$, and the expected proportion of SSTs in the search area, $E\left(p_{t}\right)$, for all possible SSTs, $t$. The search area with the least difference between expected and measured SST distributions was considered the area where the fish was located. The expected proportion of SSTs in the search area was based on a user-defined model of the expected ocean surface sampling by the fish. In this study, the fish was assumed to be sampling the surface with a bivariate Gaussian distribution of longitudes and latitudes. The mean was the center of the search area and the standard deviation was approximately one-quarter of the search area size. This distribution was used so that approximately $95 \%$ of the simulated SSTs would be within the search area. For each search area, 100 independent replicates of 50 surface samples each, were made from the remotely sensed SST grid and $E\left(p_{t}\right)$ for the search area was calculated as the modal proportions of each SST. If more than 1 search area had the same score for the third index, the median of the tied-search areas would be considered the area where the fish was located. As our knowledge of the movement patterns of each species improves, the movement model used to sample the remotely sensed SST grid could be changed to better reflect realistic sampling by the fish.

Error analysis. The errors in the light level and SST geolocation estimates were calculated as the differ- 
ences between the geolocation estimates and the mean Argos or recapture locations from the corresponding day. Prior to estimating the errors, outliers in the light level latitude estimates were removed using the iterative forward/backward averaging filter (McConnell et al. 1992). The filter removed light level latitude estimates with a daily rate of change greater than $2^{\circ}$. The errors of unfiltered light level latitude estimates were also calculated to determine the effect of this filter. Multiple pairwise bootstrap hypothesis tests (1000 bootstrap samples) were used to detect any differences in the root mean square (rms) error of the various geolocation estimates (Efron \& Tibshirani 1993). The rms error was calculated by

$$
\sqrt{\frac{\sum\left(l o c_{\mathrm{est}}-10 C_{\mathrm{Argos}}\right)^{2}}{n-1}}
$$

where $l o c_{\text {est }}$ is the longitude or latitude estimated from light levels and/or SSTs, $10 c_{\text {Argos }}$ is the corresponding geolocation estimate from Argos or GPS, and $n$ is the number of samples (Hildebrand 1987). The rms error is a common error statistic and has been previously used to compare the accuracy of an estimated location (Hunter et al. 2003). If the error distribution is approximated by a Gaussian distribution with a mean of zero, it is identical to the standard deviation and the 68th percentile of the error distribution (Hildebrand 1987). To facilitate comparisons with previous studies, we report the geolocation errors using several common error statistics (Table 2).
Computer simulations of latitude estimates based on SST. A series of computer simulations were used to examine the effect of 4 factors on the accuracy of SST latitude estimates: (1) The latitude at which the tagged fish was located, (2) the number of SSTs used ( $\left.\mathrm{N}_{\mathrm{SST}}\right)$, (3) the longitude estimate error ( $\Delta$ lon), and (4) the difference between the SST measured by the tag and the remotely sensed SST at a given location $\left(\Delta \mathrm{T}_{\mathrm{SST}}\right)$.

Overall, we performed 31460 simulations, each consisting of 100 runs (52 latitude levels $\times 5 \mathrm{~N}_{\mathrm{SST}}$ levels $\times$ $11 \Delta$ lon levels $\times 11 \Delta \mathrm{T}_{\mathrm{SST}}$ levels). For each run of a simulation, 50 SSTs were randomly sampled from a remotely sensed SST grid with a bivariate Gaussian distribution of latitudes and longitudes. The mean sampling longitude was primarily $160^{\circ} \mathrm{W}$ while the mean sampling latitude was varied from 0 to $50^{\circ} \mathrm{N}$, at $1^{\circ}$ intervals. The standard deviation was fixed at $25.5 \mathrm{~km}$ so that approximately $95 \%$ of the samples would be within a $100 \times 100 \mathrm{~km}$ area. A single, equal angle, global $8 \mathrm{~d}$ mean AVHRR SST grid for the first week of 1998 was used (ftp://podaac.jpl.nasa.gov, MCSST algorithm, $18 \mathrm{~km}$ and $0.15^{\circ} \mathrm{C}$ resolution, McClain et al. 1985). This SST grid was chosen because cloud cover was negligible in the area of interest and the $18 \mathrm{~km}$ resolution significantly reduced computational time. The search area used was fixed at $100 \times 100 \mathrm{~km}$ with hemispheric latitudinal limits of $5^{\circ} \mathrm{S}$ to $70^{\circ} \mathrm{N}$. There were no constraints on the daily latitudinal change, so the algorithm searched from $5^{\circ} \mathrm{S}$ to $70^{\circ} \mathrm{N}$ to make each latitude estimate. The sampled

Table 2. Lamna ditropis, Prionace glauca and Thunnus thynnus. Error estimates for light level longitude, sea surface temperature (SST) latitude and light level latitude estimates for salmon sharks, blue sharks and Atlantic bluefin tunas. Errors were calculated as the difference between geolocation estimate and mean Argos (location class, LC $\geq 1$ ) or GPS location for the corresponding day. $\mathrm{N}$ : number of comparisons used to make error estimates; rms: root mean square. In this analysis, 2 types of data were used: PAT 2.0 data transmitted by PAT 2.0 tag, and archival data sets recovered from PAT 2.0 tags $(\mathrm{N}=8)$ or recaptured implantable archival tags $(\mathrm{N}=3)$. Light level longitude and light level latitude estimates were filtered with a $2^{\circ}$ iterative forward/backward filter $(\mathrm{McC}$ Connell et al. 1992); SST latitudes were estimated with $1^{\circ}$ constraint on daily latitudinal change and a search area of $100 \times 100 \mathrm{~km}$

\begin{tabular}{|c|c|c|c|c|c|c|c|c|}
\hline Species & $\begin{array}{l}\text { Type of } \\
\text { data }\end{array}$ & $\mathrm{N}$ & $\begin{array}{c}\text { rms error } \\
\left({ }^{\circ}\right)\end{array}$ & $\begin{array}{l}\% \text { with } \\
\text { errors }<1^{\circ}\end{array}$ & $\begin{array}{c}\text { Error range } \\
\left({ }^{\circ}\right)\end{array}$ & $\begin{array}{c}90 \% \text { CI } \\
\left({ }^{\circ}\right)\end{array}$ & $\begin{array}{c}50 \% \text { CI } \\
\left({ }^{\circ}\right)\end{array}$ & $\begin{array}{l}\text { Absolute error } \\
\left(\text { mean } \pm \mathrm{SD}^{\circ}{ }^{\circ}\right)\end{array}$ \\
\hline \multicolumn{9}{|c|}{ Light level longitude estimates } \\
\hline Salmon shark & PAT 2.0 & 92 & 0.89 & 80.4 & $-3.26-2.33$ & $-1.45-1.17$ & $-0.54-0.57$ & $0.67 \pm 0.58$ \\
\hline Blue shark & PAT 2.0 & 46 & 0.55 & 93.5 & $-1.57-1.23$ & $-1.02-0.75$ & $-0.40-0.12$ & $0.40 \pm 0.38$ \\
\hline Atlantic bluefin tuna & PAT 2.0 & 49 & 1.30 & 57.1 & $-3.22-2.16$ & $-2.27-1.64$ & $-1.47-0.49$ & $1.07 \pm 0.74$ \\
\hline Atlantic bluefin tuna & Archival & 11 & 0.78 & 81.8 & $-1.88-0.98$ & $-1.84-0.96$ & $-0.39-0.36$ & $0.58 \pm 0.55$ \\
\hline \multicolumn{9}{|l|}{ SST latitude estimates } \\
\hline Salmon shark & PAT 2.0 & 55 & 1.47 & 43.6 & $-3.20-3.06$ & $-2.53-2.09$ & $-1.36-1.06$ & $1.23 \pm 0.81$ \\
\hline Blue shark & PAT 2.0 & 33 & 1.16 & 63.6 & $-1.87-2.39$ & $-1.42-2.13$ & $-0.06-1.03$ & $0.95 \pm 0.68$ \\
\hline Atlantic bluefin tuna & PAT 2.0 & 49 & 1.89 & 53.1 & $-6.21-4.50$ & $-3.13-2.05$ & $-1.65-0.01$ & $1.41 \pm 1.28$ \\
\hline Atlantic bluefin tuna & Archival & 11 & 0.90 & 72.7 & $-1.68-1.24$ & $-1.67-1.21$ & $-0.82-0.51$ & $0.73 \pm 0.54$ \\
\hline \multicolumn{9}{|c|}{ Light level latitude estimates } \\
\hline Salmon shark & PAT 2.0 & 35 & 9.87 & 17.1 & $-1.16-18.2$ & $-0.72-17.7$ & $1.68-13.4$ & $7.68 \pm 6.29$ \\
\hline Blue shark & PAT 2.0 & 23 & 4.00 & 13.0 & $-2.81-11.4$ & $-2.25-9.59$ & $0.83-3.75$ & $3.13 \pm 2.55$ \\
\hline Atlantic bluefin tuna & PAT 2.0 & 29 & 3.93 & 17.2 & $-11.0-6.73$ & $-5.62-5.41$ & $-3.83-1.33$ & $3.19 \pm 2.33$ \\
\hline Atlantic bluefin tuna & Archival & 5 & 2.56 & 40.0 & $-4.18--0.26$ & $-4.18--0.26$ & $-3.67--0.68$ & $2.05 \pm 1.71$ \\
\hline
\end{tabular}


SSTs and the mean sampling longitude were then used to estimate the latitude.

For each simulation, all the 4 factors were held constant for 100 runs, after which, for the next simulation, we changed one factor while keeping the other 3 factors the same. Longitude $160^{\circ} \mathrm{W}$ was chosen to simulate open ocean conditions and the latitudes ( 0 to $50^{\circ} \mathrm{N}$, at $1^{\circ}$ intervals) were chosen to represent a range of SST gradients, with the mid-latitudes exhibiting the largest changes in temperature with changing latitude. In addition, a series of simulations were also performed in the Gulf Stream region $\left(74^{\circ} \mathrm{W}\right.$ and $36^{\circ} \mathrm{N}$ ) because the latitude estimate was likely to be most sensitive to $\Delta$ lon at locations where the surface isotherms were oriented in a more north to south direction. At each location, a $\Delta$ lon ranging from $-1^{\circ}$ to $+1^{\circ}$ in $0.2^{\circ}$ steps was systematically added to the longitude inputs after the SSTs were extracted from the SST grid. Similarly, a $\Delta \mathrm{T}_{\text {SST }}$ ranging from $-1^{\circ} \mathrm{C}$ to $+1^{\circ} \mathrm{C}$ in $0.2^{\circ} \mathrm{C}$ steps was also systematically added to the SST inputs used to make the latitude estimates. The number of SSTs used by the algorithm was also varied from 1 to 5 .

For each run of the simulation, the error in the latitude estimate was calculated as the difference between the mean latitude of the sampled locations and the estimated latitude. In addition, the latitudinal SST gradients were determined for each of the locations used in the simulations. A 4-way analysis of variance (ANOVA) was used to determine which of the factors affected the latitude estimates. Multiple pairwise bootstrap hypothesis tests (1000 bootstrap samples) were used to detect any differences in the rms error of the latitude estimates (Efron \& Tibshirani 1993). The latitude estimate errors were also correlated to the 4 factors.

\section{RESULTS}

\section{Shark double-tagging experiments}

Double-tagging experiments with the 2 species of sharks permitted direct comparisons of the Argosderived tracks with movements derived from light level longitudes, and latitudes based on light levels and SSTs. The tracks of the salmon sharks using light level longitude and SST latitude estimates were similar to the movements derived from Argos (Fig. 1). The average distance between a light level and SST geolocation estimate for Salmon Shark 00-775 and the corresponding Argos-derived location was $139 \pm 80 \mathrm{~km}$ (mean $\pm \mathrm{SD}$, Fig. 1). In contrast, the track of Salmon Shark 00-775 using longitudes and latitudes derived from light levels, had relatively large deviations from
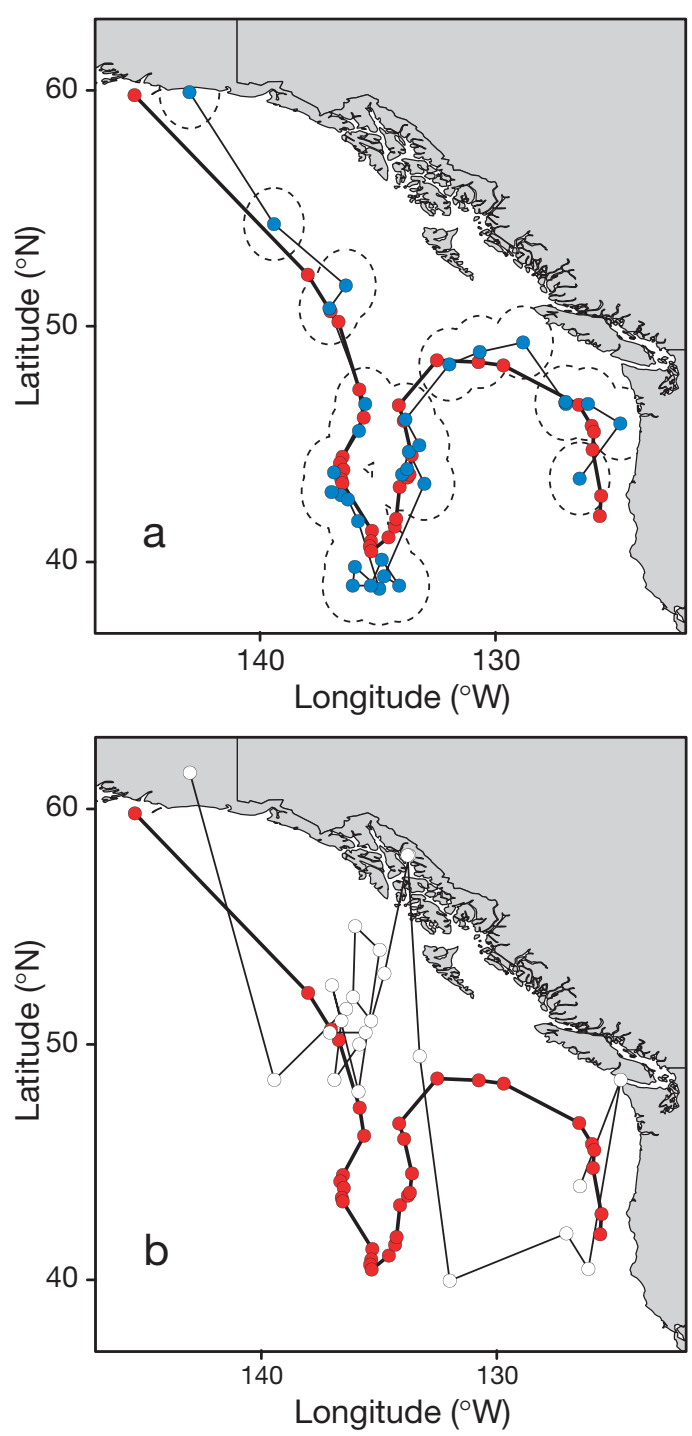

Fig. 1. Lamna ditropis. Movement of a single salmon shark double-tagged with a SPOT 2.0 satellite telemetry tag on its dorsal fin and a PAT 2.0 pop-up satellite tag (00-775, 14 July to 14 November 2002, $207 \mathrm{~cm}$ curved fork length, CFL). Track from SPOT 2.0 tag (Argos system, LC $\geq 1$, o) was compared to (a) track from PAT 2.0 tag using light level longitudes and SST latitudes (๑), and (b) track from PAT 2.0 tag using light level longitudes and light level latitudes (O). In (a) error ellipses (dashed lines) indicate $1 \mathrm{SD}$ of light level longitude and SST latitude estimates. In (b) on-land light level geolocation estimates were removed

the Argos track, with the average distance between corresponding locations being $874 \pm 577 \mathrm{~km}$ (Fig. 1). Importantly, $21 \%$ of the unfiltered light level geolocation estimates of Salmon Shark 00-775 using only light levels occurred on land. Since geolocations estimated from both light level and SST were limited to locations with SST data, none of these geolocation estimates occurred on land. 
The longitude estimates derived from light levels were similar to the Argos locations for all the double-tagged sharks. This indicates that longitude estimates derived from light levels were accurate. The longitude estimates of the salmon sharks and blue sharks had relatively low rms errors of 0.89 and $0.55^{\circ}$ respectively (Table 2). In addition, 80 and $94 \%$ of the longitude estimates for the salmon sharks and blue sharks respectively, were within $1^{\circ}$ of the Argos locations (Table 2).

The SST latitude estimates from PAT 2.0 tags were close to the Argos locations, indicating that these latitude estimates were relatively accurate (Fig. 2). The rms errors of the SST latitude estimates for the salmon sharks and blue sharks were 1.47 and $1.16^{\circ}$ respectively (Table 2). In addition, 44 and $64 \%$ of the SST latitude estimates for the salmon sharks and blue sharks respectively, were within $1^{\circ}$ of the Argos locations (Table 2). In contrast, the rms errors of the filtered light level latitude estimates for the salmon sharks and blue sharks were 9.87 and $4.00^{\circ}$ respectively (Table 2 ).

\section{Atlantic bluefin tuna experiments}

The movements based on light level longitude and SST latitude estimates from an Atlantic bluefin tuna tagged with an Mk7 archival tag (98-521) and an Atlantic bluefin tuna tagged with a PAT 2.0 pop-up satellite tag (02-608) are shown in Fig. 3. Atlantic Bluefin Tunas 98-521 and 02-608 were recaptured 461 and 152 d after tagging respectively. The great circle distances between the estimated recapture location and the reported recapture locations for 98-521 and 02-608 were 48 and $63 \mathrm{~km}$ respectively (Fig. 3). In some cases, the geolocation error as determined by the last on-fish geolocation estimate was extraordinarily low. Atlantic Bluefin Tuna 00-927 had the smallest geolocation error, with the estimated recapture location being only $5 \mathrm{~km}$ from the GPS recapture location after $90 \mathrm{~d}$ at liberty.

For the Atlantic bluefin tunas, the last on-fish geolocation estimates derived from light levels and SSTs were close to the Argos or GPS endpoint locations, indicating that these geolocation estimates were accurate (Fig. 2). Overall, the rms error in the longitude estimates was $0.78^{\circ}$ when using archival data and $1.30^{\circ}$ when using data transmitted by pop-up satellite tags (Table 2). The rms errors in the SST latitude estimates were 0.90 and $1.89^{\circ}$ when using archival data and data transmitted by pop-up satellite tags respectively
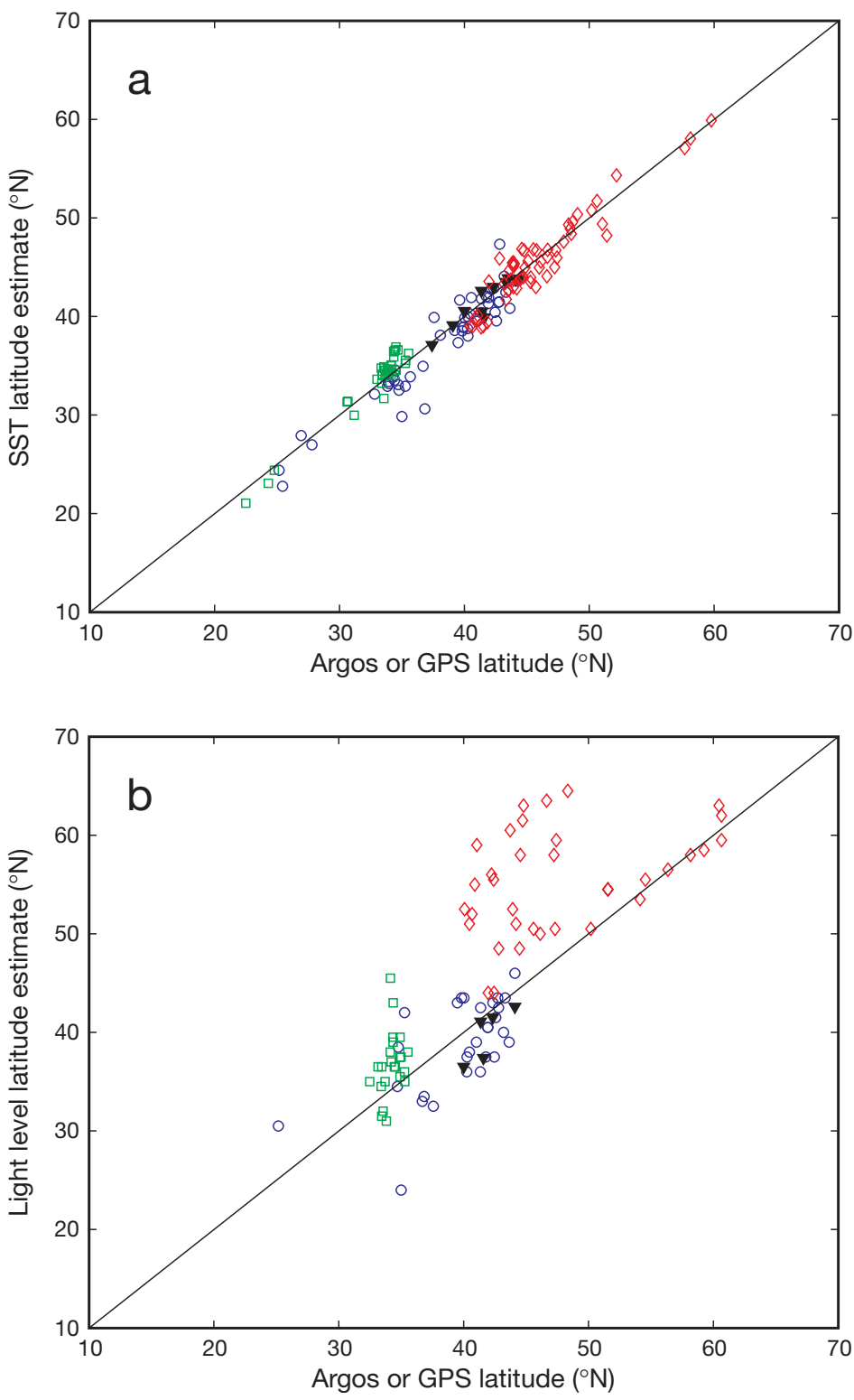

Fig. 2. Lamna ditropis, Prionace glauca and Thunnus thynnus. Correspondence of (a) SST latitude estimates, and (b) light level latitude estimates to Argos or GPS latitudes for Atlantic bluefin tunas with transmitted data $(O)$, Atlantic bluefin tunas with full archival data sets $(\boldsymbol{\nabla})$, blue sharks $(\square)$ and salmon sharks $(\diamond)$. 1:1 line is provided for visual reference

(Table 2). The rms error of longitude estimates from archival data was significantly lower than the corresponding estimates using transmitted data $(\mathrm{p}=0.046$, 1000 bootstrap samples). However, the apparent improvement in the SST latitude estimates using archival data was not significant ( $p=0.074,1000$ bootstrap samples). The rms errors of the filtered light level latitude estimates from archival data and data transmitted by the pop-up satellite tags were 2.56 and $3.93^{\circ}$ respectively (Table 2 ). 

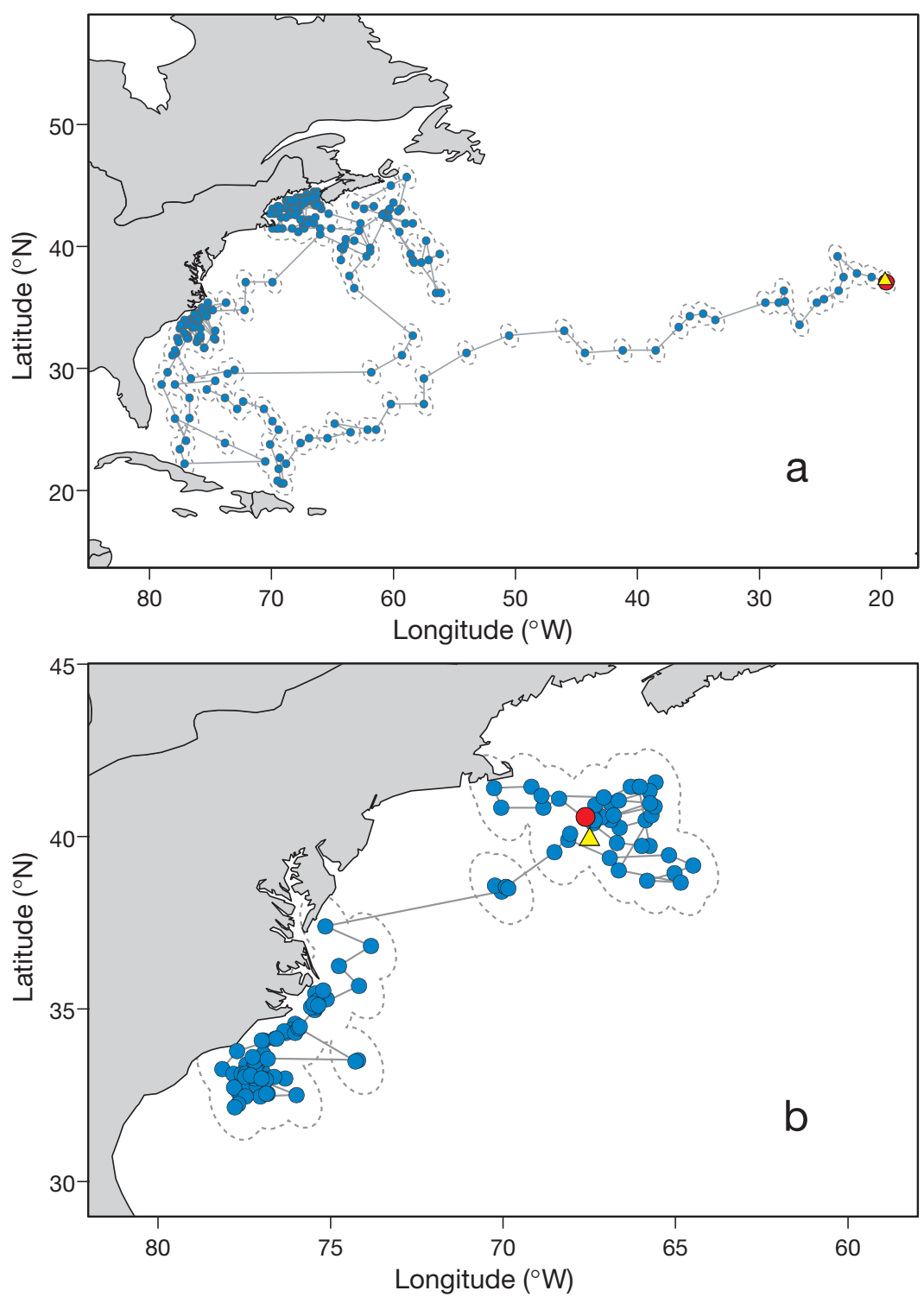

Fig. 3. Thunnus thynnus. Movements of (a) Atlantic bluefin tuna tagged with a Mk7 archival tag (98-521, 219 cm CFL: tagged 1 January 1999, recaptured 6 April 2000), and (b) Atlantic bluefin tuna tagged with a PAT 2.0 pop-up satellite tag (02-608, $211 \mathrm{~cm}$ CFL: tagged 10 January 2003, recaptured 11 June 2003). Locations were based on light level longitude and SST latitude estimates (๑). Estimated recapture locations based on light level longitude and SST latitude estimates $(\odot)$ and reported GPS recapture locations from fishers $(\triangle)$ are shown

provements in the latitude estimates were not significant for the blue sharks or the Atlantic bluefin tunas ( $p>0.05,1000$ bootstrap samples).

The use of a $1^{\circ}$ constraint on the daily latitudinal change improved some of the SST latitude estimates (Table 3). For salmon sharks, using a $1^{\circ}$ constraint resulted in latitude estimates with an rms error significantly lower than the estimates made without any constraint $(p<0.001,1000$ bootstrap samples). However, the apparent improvements in the latitude estimates were not significant for the blue sharks ( $p=$ $0.14,1000$ bootstrap samples) and Atlantic bluefin tunas using transmitted data ( $\mathrm{p}=$ 0.098, 1000 bootstrap samples). Using archival data, the rms errors of the latitude estimates from Atlantic bluefin tunas, with and without constraints, appeared to be similar ( $p=0.568,1000$ bootstrap samples).

An iterative forward/backward filter (McConnell et al. 1992) was used to remove concurrent light level longitude estimates that were more than $2^{\circ}$ apart. However, the filter did not affect the accuracy of the longitude estimates. For the salmon sharks, the rms error of the unfiltered longitude estimates $\left(1.02^{\circ}\right)$ was not significantly different from the filtered estimates $\left(0.89^{\circ}, \mathrm{p}=0.671\right.$, 1000 bootstrap samples). The filter removed $4 \%$ of the salmon shark longitude estimates. For the blue sharks and Atlantic bluefin tunas, the errors for filtered and unfiltered longitude estimates were identical because the filter did not remove any longitude estimates used to determine the errors.

An iterative forward/backward filter (McConnell et al. 1992) was also used to remove concurrent light level latitude estimates that were more than $2^{\circ}$ apart. The filter appeared to improve the light level latitude estimates for all 3 species but these improvements were not significant $(p>$ 0.05, 1000 bootstrap samples, Table 4). However, the filter removed a large num-

\section{Effects of search area size and filters}

The use of a search area of $100 \times 100 \mathrm{~km}$ improved some of the SST latitude estimates (Table 3). For salmon sharks, the rms error of latitude estimates using a $100 \times 100 \mathrm{~km}$ search area was significantly lower than when using a search area of $50 \times 50 \mathrm{~km}(\mathrm{p}<0.001$, 1000 bootstrap samples) or $200 \times 200 \mathrm{~km}(\mathrm{p}<0.001$, 1000 bootstrap samples). However, the apparent im- ber of latitude estimates for all 3 species, with up to $62 \%$ of the salmon shark latitude estimates being removed (Table 4 ).

\section{Computer simulations of latitude estimates based on SST}

The computer simulations showed that the SSTbased algorithm was able to accurately and precisely 
Table 3. Lamna ditropis, Prionace glauca and Thunnus thynnus. Effect of changing search area size and imposing a $1^{\circ}$ constraint on daily latitudinal change on root mean square errors of SST latitude estimates for salmon sharks, blue sharks and Atlantic bluefin tunas. ${ }^{*}$ Root mean square error is significantly different from that with a $100 \times 100 \mathrm{~km}$ search area and a $1^{\circ}$ constraint on daily latitudinal change ( $\mathrm{p}<0.001,1000$ bootstrap samples). Type of data as in Table 2

\begin{tabular}{|c|c|c|c|c|c|}
\hline \multirow[t]{2}{*}{ Species } & \multirow{2}{*}{$\begin{array}{l}\text { Type } \\
\text { of data }\end{array}$} & \multicolumn{4}{|c|}{ Root mean square error of SST latitude estimates $\left({ }^{\circ}\right)$} \\
\hline & & $\begin{array}{c}100 \times 100 \mathrm{~km} \\
1^{\circ} \text { constraint }\end{array}$ & $\begin{array}{l}100 \times 100 \mathrm{~km} \\
\text { no constraint }\end{array}$ & $\begin{array}{c}50 \times 50 \mathrm{~km} \\
1^{\circ} \text { constraint }\end{array}$ & $\begin{array}{c}200 \times 200 \mathrm{~km} \\
1^{\circ} \text { constraint }\end{array}$ \\
\hline Salmon shark & PAT 2.0 & 1.47 & $4.48^{*}$ & $2.98^{*}$ & $4.05^{*}$ \\
\hline Blue shark & PAT 2.0 & 1.16 & 1.66 & 2.29 & 1.40 \\
\hline Atlantic bluefin tuna & PAT 2.0 & 1.89 & 4.47 & 1.76 & 1.58 \\
\hline Atlantic bluefin tuna & Archival & 0.90 & 0.85 & 2.92 & 1.62 \\
\hline
\end{tabular}

estimate latitude under open ocean conditions $\left(160^{\circ} \mathrm{W}\right.$ and 0 to $50^{\circ} \mathrm{N}$ ). Under ideal conditions $(\Delta \mathrm{lon}=0$ and $\Delta \mathrm{T}_{\mathrm{SST}}=0$ ), the overall $\mathrm{rms}$ error of the latitude estimates was $0.71^{\circ}$, and $92 \%$ of the latitude estimates were within $1^{\circ}$ of the actual locations (Fig. 4). Similarly, under ideal conditions, the Gulf Stream simulations $\left(74^{\circ} \mathrm{W}\right.$ and $\left.36^{\circ} \mathrm{N}\right)$ had an rms error of $0.45^{\circ}$, with $95 \%$ of the estimates having errors of $<1^{\circ}$.

All 4 factors significantly affected the errors of the SST latitude estimates $(\mathrm{p}<0.0001,4$-way ANOVA, Table 5). The latitude, $\Delta$ lon, $\Delta \mathrm{T}_{\mathrm{SST}}$, and the interaction between latitude and $\Delta \mathrm{T}_{\mathrm{SST}}$, appeared to be the most important factors affecting the errors of the latitude estimates $\left(R^{2}=0.84\right.$, Table 5).

The difference between the in situ SSTs measured by an electronic tag and the remotely sensed SSTs, $\Delta \mathrm{T}_{\mathrm{SST}}$, was the most important factor influencing the errors of the latitude estimates $\left(F=1.0 \times 10^{5}, \mathrm{p}<0.0001\right.$, Table 5). In general, if the SSTs measured by the electronic tag were warmer than the remotely sensed SSTs $\left(\Delta \mathrm{T}_{\mathrm{SST}}>0\right)$, the latitude estimates erred towards the equator, and vice versa (Fig. 5). The effect of $\Delta \mathrm{T}_{\mathrm{SST}}$ was also significantly affected by latitude $\left(F=8.91 \times 10^{3}\right.$, $\mathrm{p}<0.0001$, Table 5). This was primarily due to the

Table 4. Lamna ditropis, Prionace glauca and Thunnus thynnus. Effect of filtering light level latitude estimates with a $2^{\circ}$ iterative forward/backward filter (McConnell et al. 1992) for salmon sharks, blue sharks and Atlantic bluefin tunas. There were no significant differences between root mean square errors of filtered and unfiltered estimates for any species ( $p>0.05,1000$ bootstrap samples). Type of data as in Table 2. Nos. in parentheses: number of available locations used to calculate root mean square errors

\begin{tabular}{|c|c|c|c|}
\hline \multirow[t]{2}{*}{ Species } & \multirow[t]{2}{*}{$\begin{array}{l}\text { Type } \\
\text { of data }\end{array}$} & \multicolumn{2}{|c|}{$\begin{array}{l}\text { Root mean square } \\
\text { error of light level } \\
\text { latitude estimates }\left(^{\circ}\right)\end{array}$} \\
\hline & & $2^{\circ}$ filter & No filter \\
\hline Salmon shark & PAT 2.0 & $9.87(35)$ & $11.2(92)$ \\
\hline Blue shark & PAT 2.0 & $4.00(23)$ & $6.59(46)$ \\
\hline Atlantic bluefin tuna & PAT 2.0 & $3.93(29)$ & $6.77(49)$ \\
\hline Atlantic bluefin tuna & Archival & $2.56(5)$ & $8.05(11)$ \\
\hline
\end{tabular}

differences in the SST gradient at different latitudes. For example, the slope of the relationship between $\Delta \mathrm{T}_{\mathrm{SST}}$ and the latitude estimate errors was significantly shallower ( $\mathrm{p}<0.001,1000$ bootstrap samples) at $36^{\circ} \mathrm{N}$ than at $15^{\circ} \mathrm{N}$ (Fig. 5). This was the result of the differences in the SST gradients, which were steeper in the mid-latitudes (Fig. 6). The errors of the latitude estimates were significantly inversely correlated to the SST gradients $\left(\mathrm{R}^{2}=0.64, \mathrm{p}<0.001\right.$, Fig. 6).

The latitude at which the estimate was made, also significantly affected the accuracy of the latitude estimates $\left(F=2.1 \times 10^{4}, \mathrm{p}<0.0001\right.$, Table 5). Even when $\Delta \mathrm{T}_{\mathrm{SST}}=0$, the latitude estimates appeared to be less variable in the mid-latitudes (Fig. 6). The region between 30 and $45^{\circ} \mathrm{N}$ had the steepest SST gradient (Fig. 6), suggesting that the steep SST gradients at the mid-latitudes improved the precision of the latitude estimates.

The longitude estimate error, $\Delta$ lon, played a small but significant role in influencing the errors of the

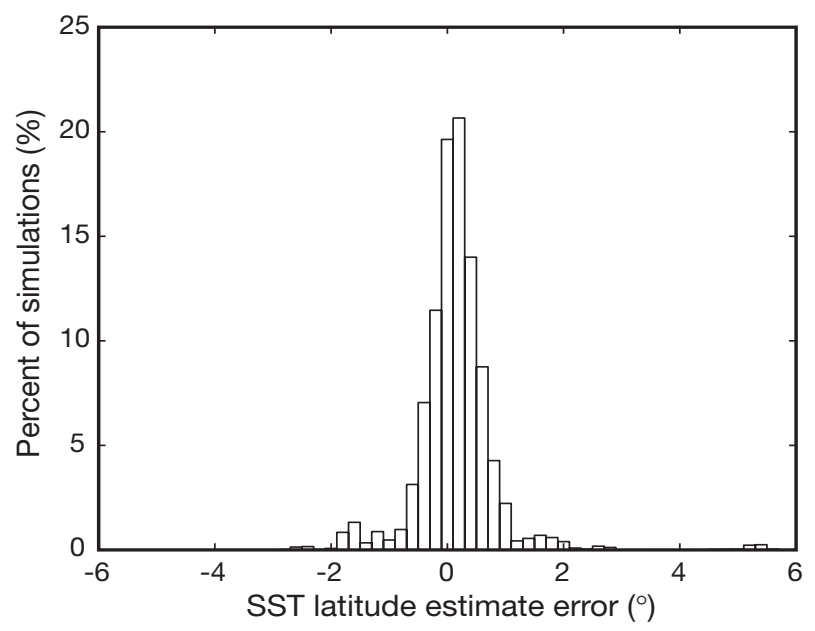

Fig. 4. Error distribution of SST latitude estimates from computer simulations in the open ocean ( $\mathrm{n}=25500$ runs) with no longitude estimate error and no difference between SSTs measured by tag and the remotely sensed SSTs $(\Delta$ lon $=0$ and $\Delta \mathrm{T}_{\mathrm{SST}}=0$ ). Simulations based on longitude of $160^{\circ} \mathrm{W}$ and latitudes from 0 to $50^{\circ} \mathrm{N}$ at $1^{\circ}$ intervals and using 1 to 5 SSTs 
Table 5. Results of 4-way ANOVA with first-order interaction, of SST latitude estimate errors from computer simulations along $160^{\circ} \mathrm{W}(\mathrm{n}=$ 3085500 runs, $R^{2}=0.848$ ). The 4 factors were (1) latitude of fish, (2) number of SSTs used $\left(\mathrm{N}_{\mathrm{SST}}\right)$, (3) longitude estimate error $(\Delta \mathrm{lon})$, and (4) difference between SSTs measured by the tag and the remotely sensed SSTs $\left(\Delta \mathrm{T}_{\mathrm{SST}}\right)$

\begin{tabular}{|c|c|c|c|c|c|}
\hline Source & $\mathrm{DF}$ & Type 3 SS & Mean square & $F$-value & $\mathrm{p}>F$ \\
\hline Latitude $^{a}$ & 50 & $9.96 \times 10^{5}$ & $1.99 \times 10^{4}$ & $2.10 \times 10^{4}$ & $<0.0001$ \\
\hline$\Delta \operatorname{lon}^{\mathrm{a}}$ & 10 & $1.42 \times 10^{4}$ & $1.42 \times 10^{3}$ & $1.49 \times 10^{3}$ & $<0.0001$ \\
\hline$\Delta \mathrm{T}_{\mathrm{SST}}^{\mathrm{a}}$ & 10 & $1.09 \times 10^{7}$ & $1.09 \times 10^{6}$ & $1.00 \times 10^{5}$ & $<0.0001$ \\
\hline $\mathrm{N}_{\mathrm{SST}}$ & 4 & $5.01 \times 10^{2}$ & $1.25 \times 10^{2}$ & $1.32 \times 10^{2}$ & $<0.0001$ \\
\hline Latitude $\times \Delta \mathrm{T}_{\mathrm{SST}^{\mathrm{a}}}{ }^{\mathrm{a}}$ & 500 & $4.22 \times 10^{6}$ & $8.45 \times 10^{3}$ & $8.91 \times 10^{3}$ & $<0.0001$ \\
\hline Latitude $\times \Delta$ lon & 500 & $1.28 \times 10^{5}$ & $2.55 \times 10^{2}$ & $2.69 \times 10^{2}$ & $<0.0001$ \\
\hline Latitude $\times \mathrm{N}_{\mathrm{SST}}$ & 200 & $4.88 \times 10^{4}$ & $2.44 \times 10^{2}$ & $2.57 \times 10^{2}$ & $<0.0001$ \\
\hline$\Delta \mathrm{lon} \times \Delta \mathrm{T}_{\mathrm{SST}}$ & 100 & $1.45 \times 10^{4}$ & $1.45 \times 10^{2}$ & $1.53 \times 10^{2}$ & $<0.0001$ \\
\hline$\Delta$ lon $\times \mathrm{N}_{\mathrm{SST}}$ & 40 & $1.06 \times 10^{3}$ & 26.6 & 28.01 & $<0.0001$ \\
\hline$\Delta \mathrm{T}_{\mathrm{SST}} \times \mathrm{N}_{\mathrm{SST}}$ & 40 & $3.15 \times 10^{3}$ & 78.7 & 83.0 & $<0.0001$ \\
\hline
\end{tabular}

a These 4 factors were the largest contributors to the SST latitude estimate errors $\left(R^{2}=0.838\right)$

Increasing the number of SSTs used, $\mathrm{N}_{\mathrm{SST}}$, improved the latitude estimates. The number of SSTs was the least important of the 4 factors affecting the errors of the latitude estimates (Table 5). However, increasing $\mathrm{N}_{\mathrm{SST}}$ reduced the overall rms error of the latitude estimates (Table 6). The percentage of latitude estimates within $1^{\circ}$ of the actual latitude also increased from 90 to $94 \%$, as $\mathrm{N}_{\mathrm{SST}}$ increased from 1 to 5 (Table 6).

\section{DISCUSSION}

Electronic tags are providing extraordinary new data for discerning how animals use the ocean environment. However, it has been difficult to accurately determine the location of most fishes because their

latitude estimates $\left(F=1.49 \times 10^{3}, \mathrm{p}<0.0001\right.$, Table 5). For the simulations in the open ocean (e.g. $160^{\circ} \mathrm{W}$ and $36^{\circ} \mathrm{N}$ ), the errors of the latitude estimates were significantly correlated to $\Delta$ lon but the slope was relatively shallow $\left(\mathrm{R}^{2}=0.22, \mathrm{p}<0.0001\right.$, Fig. 7). However, the correlation of the errors to $\Delta$ lon had a significantly steeper slope $(\mathrm{p}<0.001,1000$ bootstrap samples, Fig. 7) in the Gulf Stream simulations at the same latitude $\left(74^{\circ} \mathrm{W}\right.$ and $\left.36^{\circ} \mathrm{N}\right)$. The surface isotherms at $74^{\circ} \mathrm{W}$ and $34^{\circ} \mathrm{N}$ were oriented more in a north-south direction $\left(0.702^{\circ} \mathrm{N}^{\circ} \mathrm{E}^{-1}\right)$ than at $160^{\circ} \mathrm{W}$ and $34^{\circ} \mathrm{N}\left(-0.166^{\circ} \mathrm{N}^{\circ} \mathrm{E}^{-1}\right)$. This suggests that errors in the longitude estimates play a more important role in locations where surface isotherms are oriented in a more north-south direction.

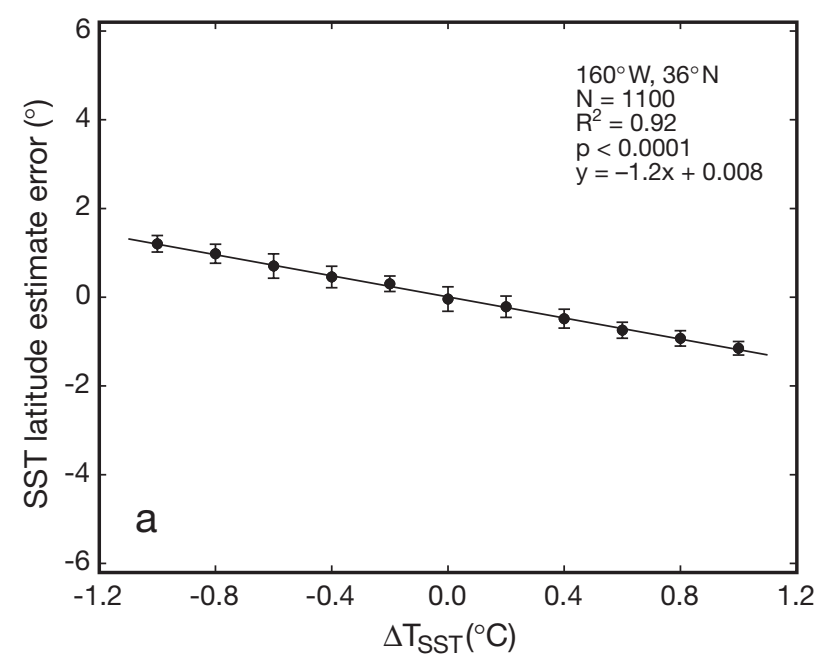

long submergence times and limited surface time have reduced the usefulness of satellite telemetry tags. An important contribution of archival and pop-up satellite tags has been the ability to geolocate animals that remain completely submerged. In order to study the behavior and ecology of these animals, which often spans ocean basins, the accuracy of geolocation estimates from electronic tags requires validation. In addition, the importance of the information in setting international boundaries for fisheries management mandates that the scientific community verifies the accuracy of the geolocation estimates. This paper provides experimental evidence on the accuracy and precision of the geolocation estimates derived from light levels and SSTs, using archival and pop-up satellite

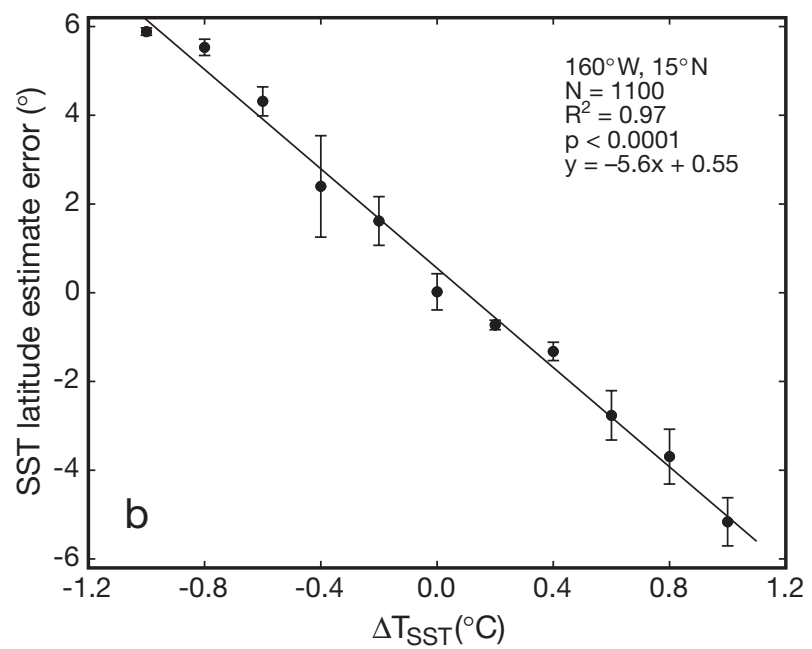

Fig. 5. Relationship between SST latitude estimate errors from computer simulations and $\Delta \mathrm{T}_{\mathrm{SST}}$, difference between $\mathrm{SSTs}$ measured by tag and remotely sensed SSTs, at (a) mid-latitude location $\left(160^{\circ} \mathrm{W}\right.$ and $\left.36^{\circ} \mathrm{N}\right)$ and, (b) low-latitude location $\left(160^{\circ} \mathrm{W}\right.$ and $\left.15^{\circ} \mathrm{N}\right)$. We used 5 SSTs and there was no longitude estimate error $(\Delta \mathrm{lon}=0)$. Error bars $=1 \mathrm{SD}$ 
Fig. 6. Latitudinal variation in SST latitude estimate errors from computer simulations ( $\mathrm{n}=16300$ runs), when SSTs were accurate $(\diamond)$, or were $1^{\circ} \mathrm{C}$ warmer $(\Delta)$ or colder $(0)$ than remotely sensed SSTs $\left(\Delta \mathrm{T}_{\mathrm{SST}}=\right.$ +1.0 and $\left.-1.0^{\circ} \mathrm{C}\right)$. Shaded area represents latitudinal SST gradient along $160^{\circ} \mathrm{W}$ meridian. We used 5 SSTs and there was no longitude estimate error $(\Delta \mathrm{lon}=0)$. Error bars $=1 \mathrm{SD}$

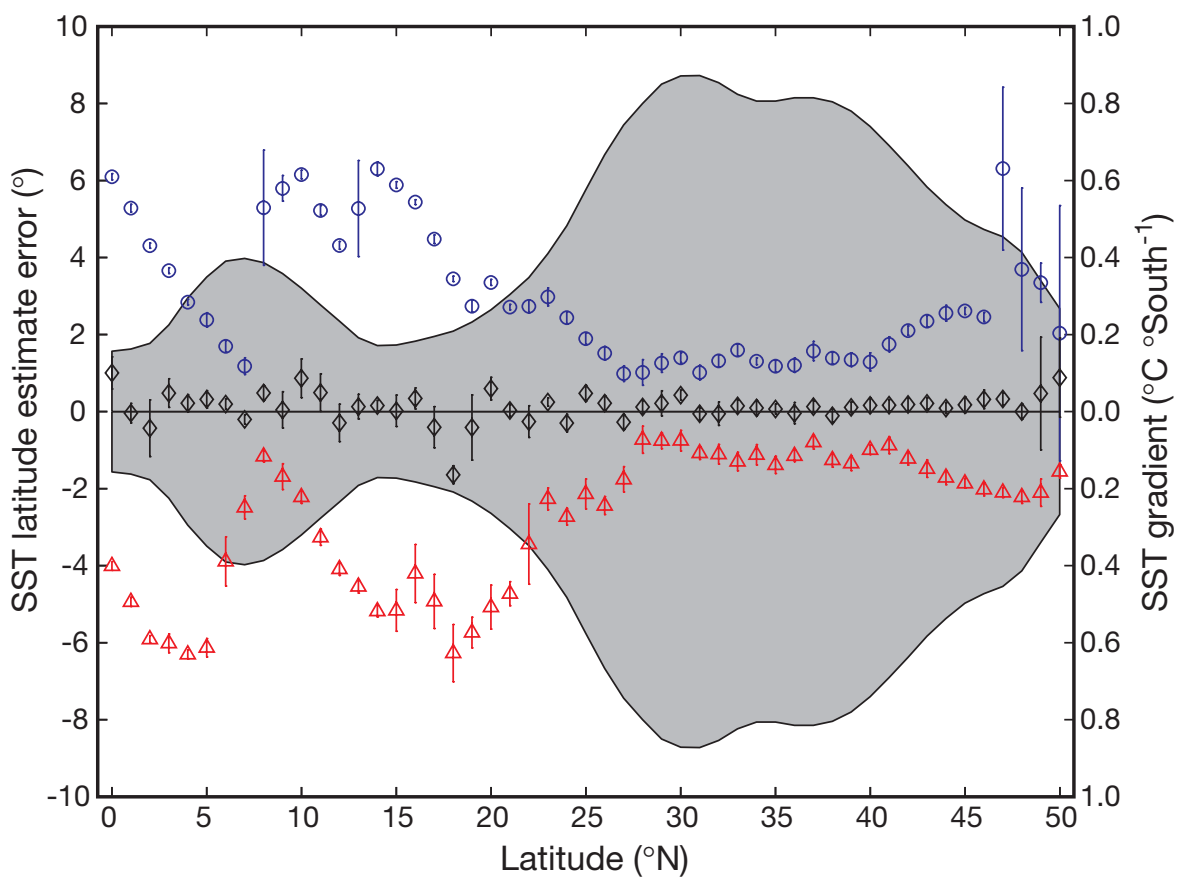

Table 6. Effect of number of SSTs used to estimate latitude $\left(\mathrm{N}_{\mathrm{SST}}\right)$ on accuracy of SST latitude estimates from computer simulations ( $\mathrm{n}=5100$ runs). There was no difference between SSTs measured by tag and remotely sensed $\mathrm{SSTs}\left(\Delta \mathrm{T}_{\mathrm{SST}}=0\right)$ and no longitude estimate error $(\Delta \mathrm{lon}=0)$. Simulations were based on longitude of $160^{\circ} \mathrm{W}$ and latitudes from 0 to $50^{\circ} \mathrm{N}$ at $1^{\circ}$ intervals

\begin{tabular}{|c|c|c|c|c|c|}
\hline & 1 & 2 & $\begin{array}{c}\text { SSTs used }\left(\mathrm{N}_{\mathrm{S}}\right. \\
3\end{array}$ & 4 & 5 \\
\hline Root mean square error $\left({ }^{\circ}\right)$ & 0.86 & 0.75 & 0.70 & 0.65 & 0.57 \\
\hline$\%$ with errors < $1^{\circ}(\%)$ & 89.7 & 89.4 & 91.6 & 93.1 & 94.2 \\
\hline $90 \% \mathrm{CI}\left({ }^{\circ}\right)$ & -0.76 to 1.12 & -0.97 to 1.06 & -0.72 to 0.92 & -0.69 to 0.85 & -0.61 to 0.85 \\
\hline
\end{tabular}
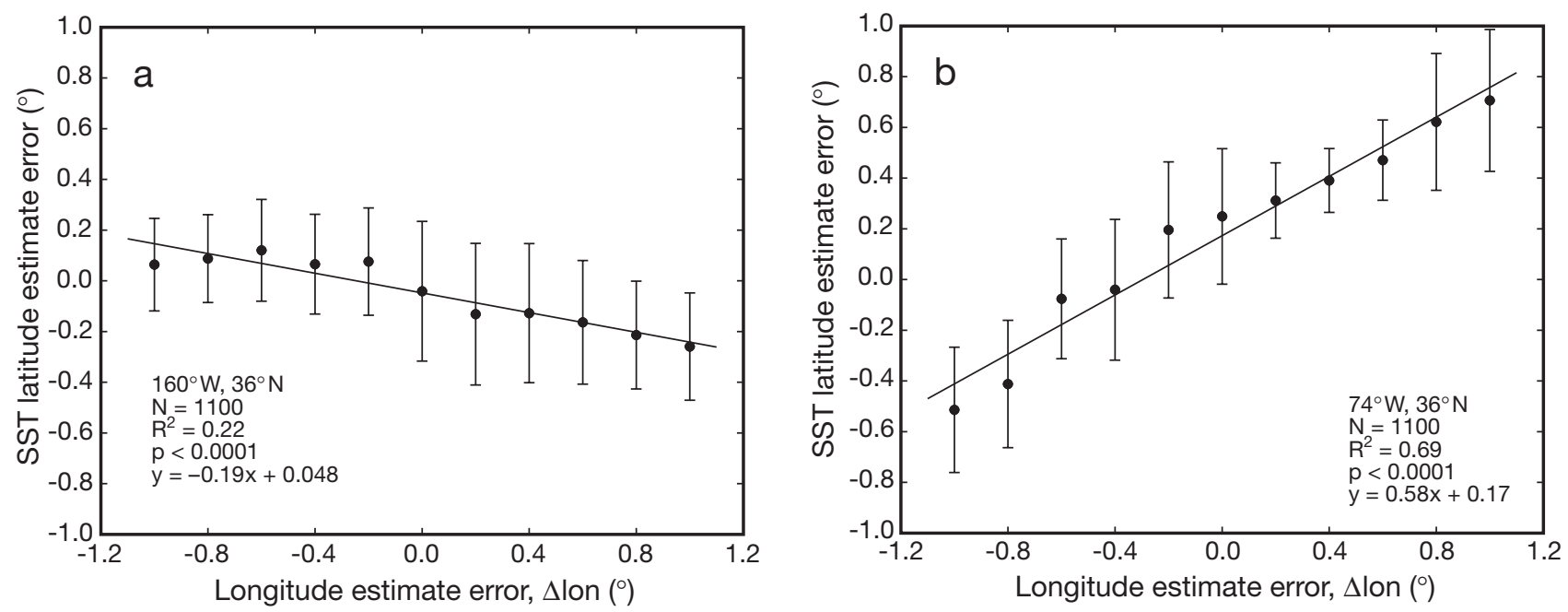

Fig. 7. Relationship between SST latitude estimate errors from computer simulations and longitude estimate errors, $\Delta$ lon, at (a) location in the open ocean $\left(160^{\circ} \mathrm{W}, 36^{\circ} \mathrm{N}\right)$ and $(\mathrm{b})$ location in the Gulf Stream region $\left(74^{\circ} \mathrm{W}, 36^{\circ} \mathrm{N}\right)$. We used $5 \mathrm{SSTs}$ and there was no difference between SSTs measured by tag and remotely sensed SSTs $\left(\Delta \mathrm{T}_{\mathrm{SST}}=0\right)$. Error bars $=1 \mathrm{SD}$ 
tags from 3 manufacturers. The objective of these experiments was to validate the accuracy and precision of geolocation estimates made with the models of electronic tags used in previous and ongoing studies of pelagic fishes.

The experiments with sharks and Atlantic bluefin tunas in the open ocean demonstrated that light level longitude and SST latitude estimates from archival and pop-up satellite tags corresponded well with the fishes' actual locations (Fig. 1). Even with an older model of pop-up satellite tag that had a relatively slow thermal response and transmitted limited amounts of SST data, it was possible to locate the sharks and Atlantic bluefin tunas within $1^{\circ}$ of their actual latitude 44 to $64 \%$ of the time (Table 2). When full archival data sets were retrieved from recovered archival or pop-up satellite tags, the rms errors of the light level longitude and SST latitude estimates were 0.78 and $0.90^{\circ}$ respectively (Table 2). Using data transmitted by pop-up satellite tags from Atlantic bluefin tunas, the rms errors of the light level longitude and SST latitude estimates were 1.30 and $1.89^{\circ}$ respectively. These errors were probably overestimates because the last on-fish geolocation estimates were made $4.3 \pm 0.5 \mathrm{~d}$ (mean $\pm \mathrm{SD}$ ) before the Argos-based pop-up endpoint locations were recorded. The results from all 3 validation methods demonstrate that geolocation estimates from electronic tags using the SST latitude algorithm accurately represent the movements of Atlantic bluefin tunas (Block et al. 2001, Stokesbury et al. in press). On an ocean basin scale, these new technologies provide a remarkable ability to geolocate actively diving animals that spend little time at the surface and span large areas of the globe.

Previous studies using electronic tags placed on buoys, ships and captive fishes have assessed the accuracy of the longitude and latitude estimates derived from light data (Gunn et al. 1994, Welch \& Eveson 1999, 2001, Musyl et al. 2001). From archival tags attached to fixed buoys at high latitudes, Welch \& Eveson (2001) reported that the absolute errors for longitude and latitude estimates based on light were $30 \pm$ $38 \mathrm{~km}\left(0.41 \pm 0.52^{\circ}\right.$, mean $\left.\pm \mathrm{SD}\right)$ and $85 \pm 110 \mathrm{~km}$ $\left(0.76 \pm 0.99^{\circ}\right)$ respectively. Similarly, Musyl et al. (2001) attached several electronic tags to fixed buoys at low latitudes and estimated a range of absolute longitude errors $\left(0.15 \pm 0.12\right.$ to $\left.0.29 \pm 0.83^{\circ}\right)$ and latitude errors $\left(1.49 \pm 2.72\right.$ to $\left.4.36 \pm 5.78^{\circ}\right)$. Gunn et al. (1994) implanted archival tags into captive Southern bluefin tunas Thunnus maccoyii swimming in a shallow, enclosed pen at mid-latitudes, and estimated absolute errors for longitude $\left(0.54 \pm 0.09^{\circ}\right)$ and latitude $(1.52 \pm$ $\left.0.22^{\circ}\right)$. The longitude estimates in this study had absolute errors ranging from $0.40 \pm 0.38$ to $1.07 \pm 0.74^{\circ}$ (Table 2). The latitude estimates derived from light level longitudes and SSTs also performed relatively well, with absolute errors ranging from $0.73 \pm 0.54$ to $1.41 \pm 1.28^{\circ}$ (Table 2). The slight increase in the longitude estimate error of this study was probably due to our use of free-swimming individuals, which can degrade the accuracy of light level geolocation estimates (Gunn \& Block 2001). Since the previous studies examined the accuracy of light level geolocation from tags attached to buoys, ships and pen-held fishes, the vertical movements of the tags were in all cases minimized. The use of free-swimming fishes released into the open ocean provided a test of whether such algorithms would perform well when vertical movements were not limited. In addition, having an error measurement now provides an opportunity to define the movements of Atlantic bluefin tunas, salmon sharks, blue sharks and a variety of other electronically tagged animals with a quantified error distribution, when using the specified tags. This will improve the analysis of the movements of these animals in relationship to oceanographic features (Bradshaw et al. 2002).

In this study, it was also possible to compare the accuracy of geolocation estimates made with different types of electronic tags. The geolocation estimates from recovered archival data sets appeared to be slightly better than the corresponding estimates from the transmitted data sets using pop-up satellite tags, but the improvement was not statistically significant (Table 2). This was probably due to the relatively small number of archival data sets available at this time that have an accurate endpoint location and a geolocation estimate within $5 \mathrm{~d}$ of the endpoint. As increased numbers of comparable archival data sets are examined, the improvment should become significant. The archival data sets from recovered pop-up satellite and implantable archival tags provided more data with which to make geolocation estimates, recording light level and ambient temperature data every $2 \mathrm{~min}$. A correction for the thermal inertia of the tags could therefore be applied and used to improve the accuracy of the SSTs. Archival data sets also inherently provide more SSTs and using more SSTs, will tend to improve the accuracy and precision of the latitude estimates (Table 5). In addition, the proportion of time spent at each SST can be calculated from an archival data set but not from the transmitted data. This may have improved the latitude estimates, since our algorithm uses the proportion of time spent at each SST to find the best-matching latitude. In contrast, the data sets transmitted by pop-up satellite tags only provided a limited portion of the light curve during sunrise and sunset, and the maximum and minimum SSTs for each day. Latitude differences probably did not play a major role in the differences in geolocation accuracy because for Atlantic bluefin tunas, the mean endpoint latitude of the archival data $\left(41.7^{\circ} \mathrm{N}\right)$ was similar to that of the transmitted data $\left(38.1^{\circ} \mathrm{N}\right)$. 


\section{Sources of error in latitude estimates derived from SST}

The computer simulations provided an opportunity to examine the sources of error when estimating latitudes from SST data. The most important source of error was the difference between the SSTs measured by the tag and the remotely sensed SSTs at a given location, $\Delta \mathrm{T}_{\mathrm{SST}}$. The computer simulations showed that the direction and magnitude of the error in SST latitude estimates were highly sensitive to the direction and magnitude of this temperature difference. A difference of $\pm 1.0^{\circ} \mathrm{C}$ can induce a $\pm 5.0^{\circ}$ error in the latitude estimate, depending on the location. The effect of $\Delta \mathrm{T}_{\mathrm{SST}}$ was strongest in locations with shallower latitudinal SST gradients. Therefore, minimizing this source of error is important for improving the accuracy and precision of SST latitude estimates, especially at low latitudes. This may be achieved by improving the accuracy and precision of both the remotely sensed SSTs and the SSTs measured by the tag. A newer model of pop-up satellite tag (PAT 3.0, Wildlife Computers) has a quick response thermistor and it will be interesting to see if the accuracy of the SST latitude estimates improves.

Atmospheric and oceanographic conditions are known to affect the accuracy of remotely sensed SSTs and hence the direction and magnitude of $\Delta \mathrm{T}_{\mathrm{SST}}$ (Maul 1985). Although there have been substantial improvements to the resolution, coverage and accuracy of remotely sensed SST over the past years, there are still inherent errors. Cloud cover remains one of the drawbacks of using remotely sensed SST, but the accuracy and precision of the SST latitude estimates appear to be severely degraded only by high cloud cover. In this study, we used SST data from MODIS and AVHRR averaged over $8 \mathrm{~d}$. Although this greatly reduced the area with high cloud cover, it may have resulted in a larger $\Delta \mathrm{T}_{\mathrm{SST}}$. In this case, we found that $8 \mathrm{~d}$ averaged data were an adequate compromise between cloud cover and accuracy. Another challenge is that most remotely sensed SSTs are based on the infrared emissions of the skin of the ocean surface, while the in situ temperature sensors in the electronic tags measure the temperatures at a depth close to the ocean surface (Emery et al. 2001). At low wind speeds $\left(<6 \mathrm{~m} \mathrm{~s}^{-1}\right)$, the surface layer becomes poorly mixed and solar heating of the surface can substantially raise the skin temperature of the ocean (Donlon et al. 1999). Therefore, daytime remotely sensed SSTs could be substantially warmer $\left(>+1.5^{\circ} \mathrm{C}\right)$ than the in situ measurements at low wind speeds. It is therefore preferable to use SSTs at high wind speeds or nighttime SSTs for estimating latitudes.

Errors in the ambient temperature and pressure measured by the electronic tags probably contributed to the $\Delta \mathrm{T}_{\mathrm{SST}}$ in the experiments on the sharks and tunas. The ambient temperature sensors of the 3 models of implantable archival tags used in this study were situated on an external sensor stalk outside the fish's body cavity and had ambient temperature sensors with relatively fast time constants (LTD2310 = $2.4 \mathrm{~s}, \mathrm{Mk} 7=6 \mathrm{~s}, \mathrm{NMT}$ v1.1 <3 s). In contrast, the PAT 2.0 tags used in this experiment had thermistors encased within the body of the tag, resulting in a relatively long time constant of $93 \mathrm{~s}$; it therefore takes approximately $213 \mathrm{~s}$ to record $90 \%$ of a step temperature change. The likely error of a temperature measurement at a depth is related to the amount of time spent at the depth and the response time of the sensor (Emery \& Thomson 2001, Daunt et al. 2003). Hence, long response times of the temperature sensors will result in a larger $\Delta \mathrm{T}_{\mathrm{SST}}$ and less accurate SST latitude estimates. For the archival data sets from recovered PAT 2.0 and implantable archival tags, we compensated by only using archived SSTs that were recorded after the temperature sensors had equilibrated to the ambient surface temperature. However, it was not possible to do the same for PAT 2.0 tags, for which only the transmitted data set was available. In the light of this, the manufacturer of the PAT 2.0 tags has moved the thermistor to a more external position in the latest version of the PAT tag (Hardware Version 3.0), resulting in much faster thermistor responses. Efforts to calibrate the accuracy of the geolocation estimates from this new pop-up satellite tag against satellite telemetry tags on diving sharks are currently under way.

In addition to thermal inertia issues, variability and drift in the pressure sensor will also degrade the ability to determine when an animal is at the surface, and hence result in less accurate SSTs. For implantable archival tags and recovered pop-up satellite tags, the pressure data were corrected by applying a fitted polynomial to the data. During the development of software for the PAT 2.0 tags, we discerned that drift in the pressure sensor was a problem. The manufacturer subsequently enabled an onboard drift correction that checked and corrected for any drift in the pressure sensor on a daily basis. Continued improvements to the pressure sensors and the pressure-drift correction algorithms will be essential for obtaining reliable SST data.

In regions where the surface isotherms are oriented toward the north or south (e.g. the Gulf Stream region and other boundary currents), the longitude estimate error, $\Delta$ lon, strongly affects the accuracy of the SST latitude estimate. The importance of $\Delta$ lon in a region is proportional to the degree of divergence of the surface isotherms from an east-west direction. For most areas in the open ocean, the effect of $\Delta$ lon is relatively small 
compared to the effect of $\Delta \mathrm{T}_{\mathrm{SST}}$. However, in areas such as the Gulf Stream region, both $\Delta$ lon and $\Delta \mathrm{T}_{\mathrm{SST}}$ are likely to be important.

One of the possible disadvantages of the algorithm used was its potential bias to select for locations away from land. This was largely due to the second index, which summed the weighted number of pixels within the search area that matched the SSTs measured by the tag. If the search area overlapped land, the number of matching pixels within the search area might be fewer than if it did not overlap land. Therefore, the SST latitude estimate might be biased away from the coastline in these cases. A possible way to reduce this bias would be to use only the first and the third index when the location is likely to be near land, since the first and third indices do not appear to have any bias toward or away from land.

Geolocation estimates can be improved by combining different data from the same animal, including light levels, SSTs, bathymetry and tidal data, to estimate the locations (Gunn et al. 1994, Beck et al. 2002, Hunter et al. 2003). For example, Hunter et al. (2003) demonstrated the feasibility of using the timing and magnitude of the tidal cycle to estimate the locations of demersal fishes in shallow shelf areas. However, they also used bathymetry and SSTs to eliminate possible alternative locations. Although the method described by Hunter et al. (2003) is only applicable to demersal fishes, there is a general need to develop robust statistical methods for combining different types of information that will help improve geolocation estimates. Linear and nonlinear Kalman filters, and meta-analytic state-space models appear to be promising frameworks for combining multiple types of location and movement information, improving location estimates, analyzing movement patterns and providing error statistics for each geolocation estimate (Sibert \& Fournier 2001, Jonsen et al. 2003, Sibert et al. 2003). However, much work needs to be done to test the sensitivity and validity of these models using data from freeswimming animals in the ocean.

This study has shown that light level-based longitude and SST-based latitude estimates from electronic tags can be used to accurately determine marine animal movements. As researchers increase their use of electronic tags to examine individual and population movements, and develop habitat models, it is critical that errors for each position be quantified. This will also be essential for fisheries management because these geolocation data will often be used for management purposes. The errors of geolocation estimates are likely to be species-, tag- and regionspecific. It will therefore be important to quantify geolocation errors when using electronic tags or studying species other than those in this study.
Acknowledgements. This study could not have been conducted without the dedication and perseverance of the TAGA-Giant (TAG) scientific team and the Tagging of Pacific Pelagics (TOPP) shark team. We thank the captains and crews of the FVs 'Calcutta', 'Bullfrog', 'Raptor', and 'Leslie Anne' and Captain D. Branshaw of Alaska Department of Fish and Game for excellent assistance aboard the RV 'Montague'. We also thank C. Farwell, T. Williams, H. Dewar, T. Sippel and A. Seitz for long hours at sea to help generate the data set used in this analysis. We thank the National Marine Fisheries Service and Eric Prince for assisting in tag recapture. Superb assistance in tagging the blue sharks and salmon sharks was provided by D. Holts. The manuscript was improved by helpful comments from $\mathrm{H}$. Dewar and 3 anonymous reviewers. Funding was provided for TOPP by the Office of Naval Research, and for TAG by the National Marine Fisheries Service, the Packard Foundation and the Monterey Bay Aquarium Foundation. S.L.H.T. received additional support from a Stanford Graduate Fellowship and an A*STAR International Fellowship.

\section{LITERATURE CITED}

Beck CA, McMillan JI, Bowen WD (2002) An algorithm to improve geolocation positions using sea surface temperature and diving depth. Mar Mamm Sci 18:940-951

Block BA, Dewar H, Farwell C, Prince ED (1998a) A new satellite technology for tracking the movements of Atlantic bluefin tuna. Proc Natl Acad Sci USA 95:9384-9389

Block BA, Dewar H, Williams T, Prince ED, Farwell C, Fudge D (1998b) Archival tagging of Atlantic bluefin tuna (Thunnus thynnus thynnus). Mar Technol Soc J 32:37-46

Block BA, Dewar H, Blackwell S, Williams T and 7 others (2001) Electronic tags reveal migratory movements, depth preferences and thermal biology of Atlantic bluefin tuna. Science 293:1310-1314

Block B, Costa D, Boehlert G, Kochevar R (2002) Revealing pelagic habitat use: the tagging of Pacific pelagics program. Oceanol Acta 25:255-266

Boustany A, Marcinek DJ, Keen JE, Dewar H, Block BA (2001) Movements and temperature preference of Atlantic bluefin tuna (Thunnus thynnus) off North Carolina: a comparison of acoustic, archival and pop-up satellite tagging. In: Sibert JR, Nielsen JL (eds) Electronic tagging and tracking in marine fishes. Kluwer Academic Publishers, Dordrecht, p 89-108

Boustany A, Davis S, Pyle P, Anderson S, Le Boeuf B, Block B (2002) Satellite tagging-expanded niche for white sharks. Nature 415:35-36

Bradshaw CJA, Hindell MA, Michael KJ, Summer MD (2002) The optimal spatial scale for the analysis of elephant seal foraging as determined by geo-location in relation to sea surface temperatures. ICES J Mar Sci 59:770-781

Carey FG, Scharold JV (1990) Movements of blue sharks (Prionace glauca) in depth and course. Mar Biol 106: 329-342

Costa DP, Burns JM, Crocker DE, Fedak MA, Trumble S, Gales N (2001) Winter foraging ecology of crabeater seals. Am Zool 41:1417

Daunt F, Peters G, Scott B, Gremillet D, Wanless S (2003) Rapid-response recorders reveal interplay between marine physics and seabird behaviour. Mar Ecol Prog Ser 255:283-288

Delong RL, Stewart BS, Hill RD (1992) Documenting migrations of Northern elephant seals using day length. Mar Mamm Sci 8:155-159 
Donlon CJ, Nightingale TJ, Sheasby T, Turner J, Robinson IS, Emery WJ (1999) Implications of the oceanic thermal skin temperature deviation at high wind speed. Geophys Res Lett 26:2505-2508

Eckert SA, Stewart BS (2001) Telemetry and satellite tracking of whale sharks, Rhincodon typus, in the Sea of Cortez, Mexico, and the north Pacific Ocean. Environ Biol Fish 60: 299-308

Eckert SA, Dolar LL, Kooyman GL, Perrin W, Rahman RA (2002) Movements of whale sharks (Rhincodon typus) in south-east Asian waters as determined by satellite telemetry. J Zool 257:111-115

Efron B, Tibshirani RJ (1993) An introduction to the bootstrap. CRC Press LLC, Boca Raton, Fl

Ekstrom PA (2004) An advance in geolocation by light. Mem Natl Inst Polar Res (Tokyo) 58:210-226

Emery WJ, Thomson RE (2001) Data analysis methods in physical oceanography. Elsevier, Amsterdam

Emery WJ, Castro S, Wick GA, Schluessel P, Donlon C (2001) Estimating sea surface temperature from infrared satellite and in situ temperature data. Bull Am Meteorol Soc 82: 2773-2785

Graves JE, Luckhurst BE, Prince ED (2002) An evaluation of pop-up satellite tags for estimating postrelease survival of blue marlin (Makaira nigricans) from a recreational fishery. Fish Bull US 100:134-142

Gunn JS, Block BA (2001) Advances in acoustic, archival and satellite tagging of tunas. In: Block BA, Stevens ED (eds) Tunas: ecological physiology and evolution. Academic Press, San Diego, CA, p 167-224

Gunn J, Polacheck T, Davis T, Sherlock M, Betlehem A (1994) The development and use of archival tags for studying the migration, behaviour and physiology of southern bluefin tuna, with an assessment of the potential for transfer of the technology to groundfish research. ICES Mini Symposium on Fish Migration, ICES, Copenhagen, p 23

Gunn JS, Patterson TA, Pepperell JG (2003) Short-term movement and behaviour of black marlin Makaira indica in the Coral Sea as determined through a pop-up satellite archival tagging experiment. Mar Freshw Res 54:515-525

Hildebrand FB (1987) Introduction to numerical analysis. Dover Publications, Mineola, NY

Hill RD (1994) Theory of geolocation by light levels. In: Le Boeuf BJ, Laws RM (eds) Elephant seals: population ecology, behavior, and physiology. University of California Press, Berkeley, CA, p 227-236

Hill RD, Braun MJ (2001) Geolocation by light-level, the next step: latitude. In: Sibert J, Nielsen JL (eds) Electronic tagging and tracking in marine fisheries. Kluwer Academic Publishers, Dordrecht, p 443-456

Hunter E, Aldridge JN, Metcalfe JD, Arnold GP (2003) Geolocation of free-ranging fish on the European continental shelf as determined from environmental variables I. Tidal location method. Mar Biol 142:601-609

Inagake D, Yamada H, Segawa K, Okazaki M, Nitta A, Itoh T (2001) Migration of young bluefin tuna, Thunnus orientalis Temminck et Schlegel, through archival tagging experiments and its relation with oceanographic conditions in the western North Pacific. Bull Far Seas Fish Res Lab Jpn 38:53-81

Jay C, Garner G (2002) Performance of a satellite-linked GPS on Pacific walruses (Odobenus rosmarus divergens). Polar Biol 25:235-237

Jellyman D, Tsukamoto K (2002) First use of archival transmitters to track migrating freshwater eels Anguilla dieffenbachii at sea. Mar Ecol Prog Ser 233:207-215

Jonsen ID, Myers RA, Flemming JM (2003) Meta-analysis of animal movement using state-space models. Ecology 84: 3055-3063

Kearns EJ, Hanafin JA, Evans RH, Minnett PJ, Brown OB (2000) An independent assessment of pathfinder AVHRR sea surface temperature accuracy using the marine atmosphere emitted radiance interferometer (MAERI). Bull Am Meteorol Soc 81:1525-1536

Kerstetter DW, Luckhurst BE, Prince ED, Graves JE (2003) Use of pop-up satellite archival tags to demonstrate survival of blue marlin (Makaira nigricans) released from pelagic longline gear. Fish Bull 101:939-948

Kitagawa T, Nakata H, Kimura S, Tsuji S (2001) Thermoconservation mechanisms inferred from peritoneal cavity temperature in free-swimming Pacific bluefin tuna Thunnus thynnus orientalis. Mar Ecol Prog Ser 220:253-263

Kitagawa T, Nakata H, Kimura S, Sugimoto T, Yamada H (2002) Differences in vertical distribution and movement of Pacific bluefin tuna (Thunnus thynnus orientalis) among areas: the East China Sea, the Sea of Japan and the western North Pacific. Mar Freshw Res 53:245-252

Marcinek DJ, Blackwell SB, Dewar H, Freund EV, Farwell C, Dau D, Seitz AC, Block BA (2001) Depth and muscle temperature of Pacific bluefin tuna examined with acoustic and pop-up satellite tags. Mar Biol 138:869-885

Mate BR, Krutzikowsky GK, Winsor MH (2000) Satellite-monitored movements of radio-tagged bowhead whales in the Beaufort and Chukchi seas during the late-summer feeding season and fall migration. Can J Zool 78:1168-1181

Maul GA (1985) Introduction to satellite oceanography. Kluwer Academic, Hingham, MA

McClain EP, Pichel WG, Walton CC (1985) Comparative performance of AVHRR-based multichannel sea-surface temperatures. J Geophys Res C 90:1587-1601

McConnell BJ, Chambers RC, Fedak MA (1992) Foraging ecology of Southern elephant seals in relation to the bathymetry and productivity of the Southern Ocean. Antarct Sci 4:393-398

McConnell BJ, Fedak MA, Lovell P, Hammond PS (1999) Movements and foraging areas of grey seals in the North Sea. J Appl Ecol 36:573-590

Metcalfe JD, Arnold GP (1997) Tracking fish with electronic tags. Nature 12:665-666

Musyl MK, Brill RW, Curran DS, Gunn JS and 6 others (2001) Ability of archival tags to provide estimates of geographical position based on light intensity. In: Sibert JR, Nielsen JL (eds) Electronic tagging and tracking in marine fisheries. Kluwer Academic Publishers, Dordrecht, p 343-367

Musyl MK, Brill RW, Boggs CH, Curran DS, Kazama TK, Seki MP (2003) Vertical movements of bigeye tuna (Thunnus obesus) associated with islands, buoys, and seamounts near the main Hawaiian Islands from archival tagging data. Fish Oceanogr 12:152-169

Nichols WJ, Resendiz A, Seminoff JA, Resendiz B (2000) Transpacific migration of a loggerhead turtle monitored by satellite telemetry. Bull Mar Sci 67:937-947

Phillips RA, Silk JRD, Croxall JP, Briggs DR (2004) Accuracy of geolocation estimates for flying seabirds. Mar Ecol Prog Ser 266:265-272

Polovina JJ, Kobayashi DR, Parker DM, Seki MP, Balazs GH (2000) Turtles on the edge: movement of loggerhead turtles (Caretta caretta) along oceanic fronts, spanning longline fishing grounds in the central North Pacific 1997-1998. Fish Oceanogr 9:71-82

Polovina JJ, Howell E, Kobayashi DR, Seki MP (2001) The transition zone chlorophyll front: a dynamic global feature defining migration and forage habitat for marine resources. Prog Oceanogr 49:469-483 
Priede I (1984) A basking shark (Cetorhinus maximus) tracked by satellite together with simultaneous remote sensing. Fish Res 2:201-216

Schaefer KM, Fuller DW (2002) Movements, behavior, and habitat selection of bigeye tuna (Thunnus obesus) in the eastern equatorial Pacific, ascertained through archival tags. Fish Bull 100:765-788

Seitz AC, Weng KC, Boustany AM, Block BA (2002) Behaviour of a sharptail mola in the Gulf of Mexico. J Fish Biol 60:1597-1602

Sibert JR, Fournier DA (2001) Possible models for combining tracking data with conventional data. In: Sibert JR, Nielsen JL (eds) Electronic tagging and tracking in marine fisheries. Kluwer Academic Publishers, Dordrecht, p 443-456

Sibert JR, Musyl MK, Brill RW (2003) Horizontal movements of bigeye tuna (Thunnus obesus) near Hawaii determined by Kalman filter analysis of archival tagging data. Fish Oceanogr 12:141-151

Sims D, Southall E, Richardson A, Reid P, Metcalfe J (2003) Seasonal movements and behaviour of basking sharks from archival tagging: no evidence of winter hibernation. Mar Ecol Prog Ser 248:187-196

Sisak MM (1998) Animal-borne GPS and the deployment of a GPS based archiving datalogger on Hawaiian monk seal (Monachus schauinslandi). Mar Technol Soc J 32:30-36

Smith P, Goodman D (1986) Determining fish movements from an 'archival' tag: precision of geographical positions made from a time series of swimming temperature and depth. Report No. NOAA Tech Memo NMFS SWFC60:1-13

Stokesbury MJ, Teo SLH, Seitz A, O'Dor RK, Block BA (in press) Movement of Atlantic bluefin tuna (Thunnus thynnus) as determined by satellite tagging experiments initiated off New England. Can J Fish Aquat Sci

Editorial responsibility: Otto Kinne (Editor),

Oldendorf/Luhe, Germany
Taillade M (1992) Animal tracking by satellite. In: Priede IG, Swift SM (eds) Wildlife telemetry: remote monitoring and tracking of animals. Ellis Horwood, London, p 149-160

Takahashi M, Okamura H, Yokawa K, Okazaki M (2003) Swimming behaviour and migration of a swordfish recorded by an archival tag. Mar Freshw Res 54:527-534

Vincent C, McConnell B, Ridoux V, Fedak M (2002) Assessment of Argos location accuracy from satellite tags deployed on captive gray seals. Mar Mamm Sci 18:156-166

Wan ZM, Zhang YL, Li ZL, Wang RB, Salomonson VV, Yves A, Bosseno R, Hanocq JF (2002) Preliminary estimate of calibration of the moderate resolution imaging spectroradiometer thermal infrared data using Lake Titicaca. Remote Sens Environ 80:497-515

Weimerskirch H, Bonadonna F, Bailleul F, Mabille G, Dell'Omo G, Lipp HP (2002) GPS tracking of foraging albatrosses. Science 295:1259

Welch DW, Eveson JP (1999) An assessment of light-based geoposition estimates from archival tags. Can J Fish Aquat Sci 56:1317-1327

Welch DW, Eveson JP (2001) Recent progress in estimating geoposition using daylight. In: Sibert JR, Nielsen JL (eds) Electronic tagging and tracking in marine fisheries. Kluwer Academic Publishers, Dordrecht, p 369-383

Weng KC, Block BA (2004) Diel vertical migration of the bigeye thresher shark (Alopia superciliosus), a species possessing orbital retia mirabilia. Fish Bull 102:221-229

West GJ, Stevens JD (2001) Archival tagging of school shark Galeorhinus galeus in Australia: initial results. Environ Biol Fish 60:283-298

Wilson RP, Ducamp JJ, Rees GW, Culik BM, Niekamp K (1992) Estimation of location: global coverage using light intensity. In: Priede IG, Swift SM (eds) Wildlife telemetry: remote monitoring and tracking of animals. Ellis Horwood, London, p 131-134

Submitted: October 1, 2003; Accepted: May 5, 2004

Proofs received from author(s): November 17, 2004 